\title{
The Choice between Formal and Informal Intellectual Property: A Review
}

\author{
Bronwyn Hall, Christian Helmers, Mark Rogers, and Vania Sena*
}

We survey the economic literature, both theoretical and empirical, on the choice of intellectual property protection by firms. Our focus is on the trade-offs between using patents and disclosing versus the use of secrecy, although we also look briefly at the use of other means of formal intellectual property protection. (JEL D82, K11, O31, O34)

Trade secret law provides far weaker protection in many respects than the patent law. [.. .] The possibility that an inventor who believes his invention meets the standards of patentability will sit back, rely on trade secret law, and after one year of use forfeit any right to patent protection [...] is remote indeed.

US Supreme Court (Kewanee Oil Co. v. Bicron Corp., 416 U.S. 470, 1974)

\footnotetext{
*Hall: University of California, Berkeley, University of Maastricht, NBER, IFS, and NIESR. Helmers: Santa Clara University. The late Rogers: formerly of Harris Manchester College at Oxford University. Sena: University of Essex. We gratefully acknowledge funding from the UK Intellectual Property Office. We thank Beth Webster, Ivan Png, John Walsh and four anonymous referees for valuable and helpful comments. This work contains statistical data from UK ONS, which is Crown copyright and reproduced with the permission of the controller of HMSO and Queen's Printer for Scotland. The use of the ONS statistical data in this work does not imply the endorsement of the ONS in relation to the interpretation or analysis of the statistical data. This work uses research datasets, which may not exactly reproduce National Statistics aggregates.

'Go to http://dx.doi.org/10.1257/jel.52.2.375 to visit the article page and view author disclosure statement(s).
}

Judges and lawyers have sometimes thought that because trade secret law provides less protection to the inventor than patent law does, no rational person with a patentable invention would fail to seek a patent. [...] This reasoning is incorrect.

Friedman, Landes, and Posner

(1991: 62-63)

\section{Introduction}

\$500,000 per patent: this figure circulated Widely following Google's announcement of its takeover of Motorola (Economist 17vAugust 2011). This value is obtained by dividing the price paid by Google for the acquisition of Motorola (US\$12.5 billion) by the number of patents held by Motorola $(24,000)$. Applying a similar logic, the acquisition of the patents assigned to Canadian Nortel by a consortium of firms in July 2011 yields an even higher price tag of $\$ 750,000$ per patent! ${ }^{1}$ These figures may seem

\footnotetext{
${ }^{1}$ The consortium comprised Microsoft, Apple, Ericsson, EMC, Sony, and Research in Motion.
} 
extreme, however, data covering a broader range of patent transactions suggests that the average price of traded United States Patent and Trademark Office (USPTO) patents in 2012 was around $\$ 370,000 .{ }^{2}$ Comparing the trading value of commercial secrets is more difficult, since the trading of secrets is, by definition, much harder to observe empirically, but some figures can still be obtained from court rulings. For example, in a recent ruling by a federal court in Virginia in September 2011, Kolon Industries Inc. was held liable to paying DuPont Co. the amount of $\$ 919.9$ million for the theft of 149 trade secrets related to the production of Kevlar, a special fiber (Bloomberg 15 September 2011). This suggests an average value of $\$ 6.3$ million per trade secret.

These computations are certainly naïve, but the figures nevertheless indicate that firms use both patents and trade secrets to protect valuable inventions and, contrary to a commonly encountered belief, patents may not necessarily protect a company's most valuable inventions. Such inventions may be kept secret despite being patentable.

The economics literature has focused overwhelmingly on the use of patents by companies as a means to appropriating returns to innovation. 3 Recent events related to the enforcement of patents on digital data transmission technologies in courts around the globe have reinforced the impression that innovation-in particular high-tech innovation-is inextricably linked with patents. The previously cited court case on the misappropriation of Kevlar trade secrets, however, shows that firms choose secrecy over patenting, even for high-tech products that are patentable. In fact, the available empirical evidence, which is reviewed in more detail below, strongly suggests that only a small

\footnotetext{
2 IPOfferings LLC Patent Value Quotient 2012.

${ }^{3}$ For the origins of the literature, see Schmookler (1966) and Comanor and Scherer (1969).
}

fraction of innovative companies relies on patents to protect their inventions. Hall et al. (2013), for example, show that, even among UK companies that conduct some form of R\&D and report to have had an innovation, only around 4 percent apply for a patent. This is much lower than would be expected if companies protected innovations through patents by default. In fact, the available survey-based evidence indicates that companies report heavier reliance on alternative mechanisms, such as lead time and secrecy (e.g., Levin et al. 1987; Cohen et al. 2000; Arundel 2001). The present article sets out to explore what we know about companies' choices of how to protect their inventions, which is directly linked with the question of how companies appropriate returns to their innovations.

It turns out the answers to these questions are far from obvious. Companies have the choice between a range of mechanisms to protect their innovative activities and output. On the one hand, they can choose formal intellectual property (IP), which includes patents, trademarks, registered designs, and copyright. On the other hand, firms can choose a range of "alternative" or informal appropriation mechanisms, such as secrecy, confidentiality agreements, lead time, or complexity. This paper reviews the theoretical and empirical literature concerning the choice among formal IP and informal appropriation mechanisms and combinations of these mechanisms in providing incentives for invention and innovation, as well as in shaping a firm's ability to commercially exploit its knowledge.

Formal IP is designed to provide ex ante incentives to innovate by providing a reward system that makes it easier for innovators to make ex post profits if their innovation is successful by allowing them to exclude imitators for a finite period. The financial reward to an IP holder derives from the legal right to exclude others from using the innovation and addresses the fundamental problem of 
appropriability that governs the production of knowledge (Arrow 1962). Appropriability is a concern for inventors, since one of the outputs of inventive and innovation activity is often knowledge, a nonexcludable intangible asset. Hence, it is difficult to keep others from using this knowledge at a fraction of the initial cost of the invention development. ${ }^{4}$ Although there may be important additional reasons for setting up an IP system, the appropriability problem is usually considered to be the basic economic justification for an IP system, because such a system allows the inventor/innovator to appropriate most of the returns from the initial innovation investment by excluding third parties from using the innovation. Nevertheless, in practice, invention and innovation do occur even if firms cannot access, or choose not to use, the IP system. As will be reviewed herein, firms use a range of mechanismssuch as secrecy or first mover advantage-by which they appropriate rewards to invention and innovation and the available empirical evidence suggests that firms rely on these alternative mechanisms much more than on formal IP. . $^{\text {. }}$

From a social point of view, granting a temporary property right on an innovation, for example in the form of a patent, is justified on the basis that the inventor is, in exchange, required to explain the innovation in a specific, standardized technical format (that can be read and understood by qualified third parties). The economic justification for this disclosure is to allow other firms to avoid duplication of research, possibly

\footnotetext{
${ }^{4}$ In some cases, the fraction may be fairly large, in that successful imitation is costly even when the imitator has acquired the relevant knowledge (Mansfield, Schwartz, and Wagner 1981).

${ }^{5}$ In basic terms, one can think of invention as being only the first step in a complex process with the end point being a successful innovation. Formally, a patent describes the invention, and not the innovation that may come later. In this paper, we do not generally refer to this distinction unless it is critical.
}

acquire useful knowledge and, when the patent expires, quickly imitate the innovation. These issues are stressed by endogenous growth theories, which demonstrate the importance of knowledge spillovers among firms and sectors for sustained long-run growth (Romer 1990). In this respect, the disclosure of knowledge required by a patent application, at least theoretically, allows knowledge to reach other firms and individual inventors and may help avoid wasteful duplication of research efforts; secrecy, on the contrary, may hinder the circulation of new ideas and therefore slow down knowledge spillovers and economic growth. ${ }^{6}$

The availability and use of the different appropriability regimes differ across technologies and sectors; some of the differences are due to differences in legal systems and exogenous characteristics of the technologies employed. Endogenous industry demographics and market structure also account for some of the observable heterogeneity across industries in firms' choices between formal and informal IP. However, the appropriability regime also depends on firms' strategic competitive behavior as discussed in detail further below.

The main forms of formal IP are patents, trademarks, designs, and copyright.] The first three of these are registered rights, while copyright is an unregistered right. In addition, trade secrecy can also be regarded as a part of IP, although in most common law countries, including the United Kingdom and the United States, trade secret law forms part of common law and, therefore, its protection is weaker than in other

\footnotetext{
${ }^{6}$ However, there is a debate about to what extent firms use patent documents to obtain information. See section 5 for more detailed discussion.

7 Other registered IP includes plant breeders' rights and semiconductor topography (mask) rights. Other unregistered IP includes unregistered designs, unregistered trademarks, and company symbols.
} 
TABLE 1

IMPORTANCE OF DifFERENT IP MECHANISMS To UK Firms 1998-2006 (\%)

\begin{tabular}{lcc}
\hline \hline & All firms & Innovators \\
\hline Formal IP & 10.6 & 27.7 \\
Patents & 10.3 & 25.8 \\
Informal IP & 18.9 & 48.5 \\
Secrecy & 21.0 & 45.3 \\
\hline
\end{tabular}

Note: Formal IP contains patents, trademarks, registered designs, and copyright; informal IP contains secrecy, lead time, complexity, confidentiality.

Data Source: UK ONS CIS 3, 4, and 5; table contains population-weighted shares based on 38,760 observations.

countries. ${ }^{\S}$ Since the underlying mechanisms differ for registered and unregistered IP, we distinguish in this review between registered IP, paying particular attention to patents as they protect technologies, and unregistered IP in the form of copyright as well as most informal mechanisms. Informal IP may take various forms; secrecy, confidentiality agreements, lead time, and complexity (of design) are subsumed under the informal IP heading. ${ }^{9}$ Similar to unregistered formal IP, informal IP remains, by construction, largely unobservable or only partially observable to third parties, which creates a formidable challenge for empirical work, as will be discussed in detail below.

The fundamental question that we address in this review is the following: for what reasons would a firm with a given innovation

\footnotetext{
${ }^{8}$ Since enforcement through common law is difficult in practice, trade secrets are often enforced through specific contracts, such as confidentiality or nondisclosure agreements. Although these documents are not a legal requirement for the enforcement of trade secrets in court, Almeling et al. $(2010,2011)$ present evidence for the United States that the secret owner is more likely to prevail against employees or business partners if such an agreement exists.

${ }^{9}$ The "informal" label does not imply the absence of legal contracts and obligations.
}

that can be protected by formal IP choose not to rely on such IP to protect an innovation? In search of explanations for this type of firm behavior, we review the theoretical literature and assess the empirical evidence to determine which of the theoretical arguments are supported by the available data. As we will discuss below, the existing evidence shows that there are enormous differences in the use of IP at the firm-level-differences that are beyond expected differences in the applicability of IP (especially patents) to firms' innovations. ${ }^{10}$ The evidence available from various firm-level surveys, which is reviewed herein, suggests that on average, firms rely more on informal than formal IP to protect their inventions, and that most firms use no IP protection at all.

Table 1 uses data collated from the UK Community Innovation Surveys (CIS) to illustrate this point. ${ }^{11}$ The table shows the percent share (using sampling weights to produce population estimates) of companies indicating medium or high importance to the company of all formal and informal IP

\footnotetext{
${ }^{10}$ See for example Rogers (2007).

${ }^{11}$ These data come from the UK CIS 3, 4, and 5, covering the years 1998-2006.
} 
TABLE 2

IMPORTANCE OF DiffERENT IP MEChanisms to U.S. Firms IN 2008 (\%)

\begin{tabular}{lcc}
\hline \hline & All firms & R\&D-doing firms \\
\hline Utility patent & 5 & 41 \\
Design patent & 6 & 33 \\
Trademark & 15 & 60 \\
Copyright & 12 & 50 \\
Trade secret & 14 & 67 \\
\hline
\end{tabular}

Note: Population-weighted share of firms that rate the IP mechanism as somewhat or very important to their firm.

Source: National Science Foundation, National Center for Science and Engineering Statistics, Business R\&D and Innovation Survey 2008. Rows may not sum to one hundred due to rounding.

protection mechanisms, as well as patenting and the use of secrecy individually. It shows that only $10-11$ percent of firms rate formal IP or patent protection as of medium or high importance, whereas about 20 percent rate some form of informal IP or secrecy as important.

Of course, one reason for not using IP protection is that there is nothing that needs protecting. In the second column of table 1 , we look at the importance rating of IP for the 30 percent of firms that have innovated during the past three years. These firms are indeed more likely to consider IP protection important, with 26-28 percent rating formal IP or patents as important and almost half rating informal IP or secrecy as important. But that still means that about half the innovating firms do not think IP is of much importance.

Table 2, drawn from the U.S. National Science Foundation's new Business R\&D and Innovation Survey (BRDIS) survey, shows similar results for U.S. firms. Looking at all firms in all industries, only a small fraction find any form of IP important to them, and the rank of importance in terms of the share of firms is trademark, trade secret, copyright, design patent, and utility patent.
When only R\&D-doing firms are considered, the shares of somewhat important and very important increase substantially, as one might expect. In this case, utility patents are still not as important as the other types of IP rights, with the exception of design patents.

Hence, understanding why firms may prefer alternative methods to protect their IP is at the heart of understanding the functioning of the IP system. If the objective of the IP system is to provide incentives to innovate, an improved understanding of why firms choose to rely on formal IP to protect innovations in some circumstances but not in others has direct implications for the design of mechanisms that set optimal incentives for firms to innovate.

Our review complements a number of existing literature reviews that have looked at the choice between different mechanisms to protect inventions. Anton, Greene, and Yao (2006) look at the choice between patents and secrecy within the context of weak patents (i.e., patents that stand a high chance of revocation in postgrant administrational or court proceedings). Their discussion focuses on the trade-off between strategically disclosing information to soften competition and the effectiveness of patents in protecting 
the disclosed information. Encaoua, Guellec, and Martínez (2006) also survey the literature on companies' decisions to patent. Their interest lies in reviewing the available evidence on whether the patent system encourages innovation.

There are some related topics that our survey does not cover. First, we have not considered the extensive literature on the private and social value of IP rights of all kinds, nor the use of IPRs as indicators of value. For these topics, see Griliches (1990) on patents as indicators, Lanjouw, Pakes, and Putnam (1998) on patent renewals, and Greenhalgh and Rogers (2007a) on the valuation of IP. Second, we have ignored the growing literature on university patenting and its implications for the open diffusion of knowledge, which is a separate and important topic that deserves its own survey. Mowery et al. (2004) provides a useful overview of the U.S. BayhDole Act and its impact.

The structure of this paper is the following. Section 2 discusses the empirical evidence on the topic that is available from firm-level surveys. Section 3 reviews the theoretical literature on the choice between patents and secrecy and section 4 summarizes the main results from empirical analysis, while section 5 briefly reviews implications for welfare analysis. Some conclusions are drawn in section 6.

\section{Survey Evidence on the Choice of IP Protection Methods}

Because there are a several ways in which a firm can protect its IP and secure returns to its innovative activity that do not require formal registration, gaining even a partial understanding of the IP choice requires asking firms about the methods they use. This method has been employed in an increasing number of countries since the 1980s and we now have survey evidence from many countries that sheds light on the choice between formal and informal IP protection tools. This section reviews the available survey evidence on the choices companies make between formal IP and alternative protection mechanisms. While the theoretical literature-which is reviewed in section 3largely focuses on the patent-secrecy tradeoff, the surveys cover a much wider range of available appropriation mechanisms. In fact, an important finding from the survey-based evidence is that companies consider some of these other appropriation mechanisms, notably lead time, to be more important than patents and secrecy. Table 3 summarizes the main findings from the surveys.

\section{1 (National) Innovation Surveys}

The seminal studies in this area are those by Levin et al. (1987)—the so-called Yale I survey-and Cohen, Nelson, and Walsh (2000) - the Carnegie Mellon survey. Neither of these works attempted to directly test the empirical implications from economic theory, but both surveys were concerned with the extent to which firms in different industries chose legal and nonlegal methods to secure returns from their inventions. The descriptive findings are broadly consistent across the two studies. On average, patents are not the most important mechanism of IP appropriation, while secrecy and lead time are, regardless of whether product or process innovations are concerned. However, this is not entirely true for product innovations and for industries that are specialized in the production of "discrete" products like pharmaceuticals and other chemicals where patents are still the favorite tool to secure the returns to IP. The survey data reveal several explanations why patents are considered more effective for product than process innovations. Processes may not be patentable; if patentable, they are more likely to disclose too much information to competitors and they are seen to be easy to invent around. 


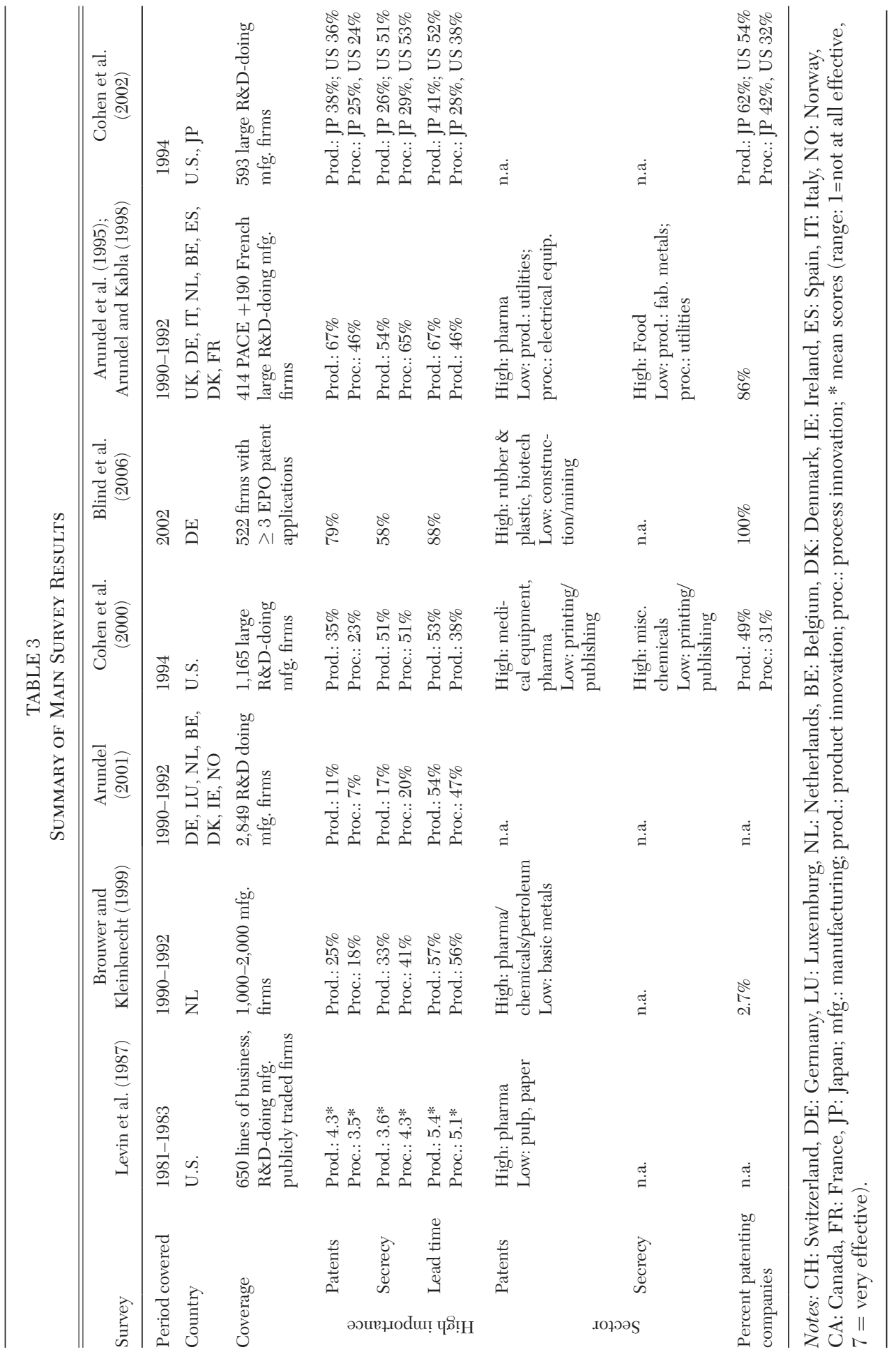


At roughly the same time as the Yale I survey (1981-83), Mansfield (1986) surveyed about one hundred U.S. manufacturing firms, asking them to what extent patent protection was essential for the commercial introduction of their inventions. Mansfield asked specifically for the share of innovations that would not have been developed or commercially introduced if patent protection had not been available. These counterfactual questions on the effect of patents at the invention level are unique to Mansfield's survey. He found that in two industries, pharmaceuticals and chemicals, patent protection was essential for 30 percent or more of the inventions. In another three industries (petroleum, machinery, and fabricated metals), patent protection was essential for about $10-20$ percent of the inventions. The remaining seven industries (electrical equipment, office equipment, motor vehicles, instruments, primary metals, rubber, and textiles) showed no reliance on patents. $\mathrm{He}$ also found that, in the five industries where patents were relatively important, 84 percent of patentable inventions were patented, whereas the share fell to 66 percent in the industries where patents were not important. His results seem consistent with those of the Yale I survey.

One of the first studies to follow up on the Yale study outside of the United States was that by Harabi (1995) for Switzerland in 1988. Using the same format as the Yale I survey, he confirmed that Swiss firms also ranked patents very low as a means of appropriating the returns to innovation, except in the chemicals (including pharmaceuticals) sector and some parts of the machinery sector. As in the Yale I study, the Swiss firms expressed concern that patents revealed too much information and that it was too easy for firms to invent around them. However, they were viewed by some firms as useful for obtaining licensing income. As in the Yale I survey, lead time was considered to be the most effective appropriation mechanism. Secrecy was seen as the second most effective appropriation mechanism-although secrecy was rated as more effective for process than product innovations.

CIS, which began in 1992 with seven European countries, included a range of questions on the mechanisms available to companies to appropriate returns to innovating. ${ }^{12}$ The wording of a typical question on one of these surveys is as follows: ${ }^{13}$

For the past three years, please indicate the importance to your enterprise of each of the following methods to protect innovations: patents, registration of designs, trademarks, copyright, etc.

[The respondent is asked to specify one of none, low, medium, or high.]

Brouwer and Kleinknecht (1999) use the first round of the CIS, which covers the period 1990-92, for the Netherlands to study manufacturing firms' preferences over the different appropriability mechanisms. The CIS data confirm the results from the Yale I and Swiss surveys: around half of innovating companies consider patents insignificant as protection against imitators. Lead time, keeping qualified people in the firm, and secrecy (especially for process innovations) are ranked considerably higher than patents. The CIS data also reveal large differences in the importance of patents across industries. Patents are considered to be important in chemicals and pharmaceuticals, whereas over 90 percent of firms in basic metals regard patents as unimportant. Arundel (2001) confirms these results for the first CIS survey using data for all seven countries (Germany, Luxembourg, the Netherlands, Belgium, Denmark, Ireland,

\footnotetext{
12 There was an earlier innovation survey in France during the late 1980 s that was a precursor of the CIS.

${ }^{13}$ This wording is from the CIS 3 and CIS4 in the United Kingdom. Obviously, in other countries, the question is asked in the appropriate language and may therefore vary slightly from survey to survey.
} 
and Norway). The results show that firms systematically regard lead time and secrecy as more important ways to protect their IP than patents. Over 50 percent of firms rank lead time as the most important mechanism to appropriate returns to their innovation and nearly 17 percent regard secrecy as the most important way to protect an innovation. In contrast, only about 10 percent regard patents as the most effective way to secure returns and only about 3 percent consider registered designs as the most important way to exploit an innovation. The relative greater importance of secrecy applies to firms across different size categories, although smaller firms regard secrecy as even more important than larger companies.

While these studies are informative about the importance and effectiveness attributed by firms to the different mechanisms, there are no data on firms' actual patenting activities. Hall et al. (2013) combine three rounds of CIS data for the UK (1998-2006) with firms' actual patent filings to show that only a small share (4 percent) of innovative companies in the United Kingdom patents. Again, companies rate lead time, confidentiality agreements and secrecy higher than patents as mechanisms to protect their innovations. Hardly surprisingly, patenting companies regard patents as much more effective a mechanism to protect innovations than firms that do not patent. However, there is hardly any difference between companies that patent and those that do not with regard to how important secrecy or lead time is rated by companies. The results also show that the decision to patent by innovative companies is largely explained by a few factors: the type of activity carried out by a firm (industry), size, and the type of innovation companies produce (product innovations that are new to the market).

In the United States, there is no equivalent to the European CIS. But the National Science Foundation and the U.S. Census
Bureau launched the BRDIS in 2009. The survey collects data on firms' R\&D spending and innovative as well as patenting activities and is thus a lot broader than the Survey of Industrial Research and Development that it replaced. The survey has a number of advantages over the CIS: it collects data on global activities of companies operating in the United States, it asks for R\&D employee headcounts by occupation category, and it separates sales and R\&D data by business activity. So far only a few results have been released. The survey reveals that in 2008, 21 percent of R\&D performing companies applied for a patent (U.S. National Science Foundation 2012). Shares vary widely across industries: more than 60 percent of companies patented in basic chemicals whereas less than 10 percent patented in food. In any case, these figures are significantly higher than the figures found by Hall et al. (2013) for the United Kingdom..$^{14}$

There is also growing survey evidence from countries other than the United States or Europe. ${ }^{15}$ Hanel (2008) for example reports results from a 1999 survey of Canadian manufacturing firms. The results are very similar to those for U.S. and European firms. Companies consistently regard alternative mechanisms, especially confidentiality agreements, as more important than patents. Interestingly firms also rate trademarks higher than patents. As in the U.S. and European surveys, patents are nevertheless important in discrete technologies, pharmaceuticals, chemicals, and plastics.

\footnotetext{
${ }^{14}$ Hall et al. (2013) use a broader definition of R\&D, which means the sample contains a broader range of companies. The companies in the U.S. sample may also take into consideration patent filings by foreign affiliates. Moreover, the difference may also be partly due to undercounting of patents by Hall et al. (2013) on the one hand (because patents have to be matched by name to companies) and overreporting by companies in the U.S. survey.

15 Innovation surveys following the CIS model are conducted in a wide range of countries, including middle income economies, for example Brazil's PINTEC survey.
} 
The survey also suggests that innovators of "new-to-the-world" innovations rely more on patents than secrecy. This is expected, given the novelty requirement for patenting, but it also suggests a positive correlation between the value of innovations and the propensity to patent them.

So far we focused in the discussion on firms' assessment of the importance of the different appropriation mechanisms for protecting innovations. Some of the surveys also offer information on motives for firms' patenting decisions. Cohen, Nelson, and Walsh (2000) find that firms in the United States use patenting for strategic reasons, rather than for protecting their IP. Respondents reported that they used patenting to block competitors, to improve goodwill reputation and to improve bargaining power in the market. A similar type of analysis conducted on a sample of patenting firms confirms these findings for Germany (Blind et al. 2006). Although most German firms indicate that they use patents primarily to protect their innovations from imitation and help secure freedom to operate, firms also use patents for offensive blocking of competitors (strategic patenting) and to improve the com-

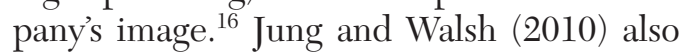
focus on patenting companies to learn about their motives for patenting. Their survey, the Georgia Tech Inventor Survey, asks a sample of U.S.-based inventors listed on triadic (filed with the USPTO, European Patent Office, and Japan Patent Office) patents for their motives to patent. The results confirm the findings by Cohen, Nelson, and Walsh (2000) and Blind et al. (2006): a substantial share of inventors lists offensive and defensive blocking as an important motivation for patenting.

\footnotetext{
${ }^{16}$ The German car manufacturer Audi provides an example for how a company's image can be influenced by its patent filings. When launching a new car model in 2006 , the company launched a multimillion dollar advertising campaign stating, "To date, NASA has filed 6,509 patents. In developing the A6, Audi filed 9,621."
}

Offensive blocking, which includes the use of patent fences, is found to be more common in discrete technologies, such as pharmaceuticals. Jung and Walsh also ask inventors for reasons why patented inventions are not used by companies, where use is defined in three ways: (1) companies exploit the patented invention themselves; (2) they license it out; or (3) they use it in a spin-out company. The most commonly cited reasons for nonuse are that no commercial use has been found yet, that the patent is used passively to block competitors and prevent inventing around, or that the invention was subject to market or technological obsolescence.

Some of the surveys discussed above also explore potential differences in the use of appropriation mechanisms between small and large firms. It is easy to see from summary table 3 that the choice of sampling frame affects the frequency with which the firms in the sample use any kind of IP protection method. For example, compare the share of firms that rate patents or secrecy of high importance in the Arundel (2001) or Brouwer and Kleinknecht (1999) sample, which covers a wide size range to the share in the Arundel, van de Paal, and Soete (1995) report, which is restricted to large $\mathrm{R} \& \mathrm{D}$ doing firms. In contrast, lead time (being first to market) is rated relatively highly in all samples.

The 2008 Berkeley Patent Survey conducted by the Berkeley Center for Law and Technology specifically targeted small, new companies in the United States (Graham et al. 2009). Graham et al. (2009) and Sichelman and Graham (2010) summarize the evidence from the information obtained on around 1,300 high-tech (biotech and software) start-ups founded in the United States since 1998. They note important differences in patenting behavior and the way in which patents are used across industries. While for some industries such as biotech, patenting is a vital part of corporate strategy, firms in 
other sectors, notably software, essentially avoid the patent system altogether. They also point out that strategic motives to patent as described previously are important for start-ups, contrasting the commonly held view that strategic patenting is only practiced by large enterprises: indeed start-ups value the reputation effect that patent ownership may bring about. Despite the importance of patents reported by biotech and medical device companies, companies still report that patents provide hardly any incentives for R\&D. The survey also asks firms directly why they choose not to patent, and it turns out that the most significant barrier to patenting (across the two industries) is financial. However, biotech firms rate concerns about the disclosure of information contained in a patent publication as a greater obstacle than costs, while the opposite is true for software. To some extent, this difference reflects the differing use of the system by firms in the two areas: biotechs worry about disclosure because they do patent (in spite of the cost), whereas software firms worry more about cost because they don't. Software companies also indicate that patents are of little use for them because enforcement would be prohibitively costly and inventing around is relatively easy, making patents ineffective. Instead, software companies consider lead time as the most important way to appropriate returns to innovating.

Whereas Graham et al. (2009) focus on start-up companies, Hyytinen and Pajarinen (2003, 2005) and Leiponen and Byma (2009) collect data on a wider set of small companies. In their survey of small Finnish companies, there is a distinction between firms' rating of the effectiveness of the different appropriability mechanisms and their actual use by companies. 25 percent of the small companies in the sample report that patents are the most important appropriability mechanism, while only 15 percent report secrecy to be the most important mechanism. This contrasts with the information on the actual use of these mechanisms. 62 percent of companies indicate that they rely on secrecy and only 16 percent report that they patent. This disagrees with Mansfield's findings for the United States, where he found that companies that indicated that patents played no important role were still found to patent the overwhelming share of their patentable inventions. The difference is probably explained by the fact that Mansfield contacted mainly large, established firms.

One important factor that needs to be considered in evaluating the results of these surveys is the position held by the respondent, especially in large firms, where there is considerable differentiation in areas of responsibility. Many of the surveys of R\&D-doing firms are directed to the R\&D manager, as in the case of Levin et al. (1987); the CIS questionnaires do not specify who should fill them out. In contrast to the majority of the surveys, Cockburn and Henderson (2003) survey senior IP in-house counsels across a range of industries in the United States. The data collected from IP counsels suggest that the availability of patents has an important positive effect on R\&D spending. IP counsels do not think that patents reveal too much valuable information to competitors. Moreover, patents are seen as important instruments to settle IP disputes and avoid litigation. Half of all the respondents to this survey identify patents as the company's most valuable IP asset, and trade secrets are only seen by 12 percent of respondents as a company's most valuable IP asset. Thus, we can safely conclude that the legal departments of firms generally rate patents more highly than either firm CEOs or R\&D managers.

The fact that survey evidence results depend on the choice of respondent tells us that we should be cautious in assigning too much numerical credibility to the shares that result. In particular it may be somewhat misleading to compare across surveys unless 
the questions and the types of respondents are identical. Nevertheless, without these surveys we would perhaps not have learned the extent to which firms rely on informal methods like lead time, secrecy, product complexity, and sales and service activity to secure returns to their innovative activities, as opposed to formal methods like patents and trademarks.

\subsection{Cross-Country Comparisons}

Most empirical studies have been conducted on survey data for a single country; while this allows researchers to identify the firms' and industry characteristics that can explain firms' preference for secrecy (or for patents), single country studies do not allow the identification of the characteristics of the patent legislation that can influence this preference. For instance, in countries where the procedure to apply for a patent is very cumbersome, some firms may find the whole process so expensive that they prefer to opt for secrecy to protect their IP (see, for example, Moser (2012) for a historical comparison between Britain and the United States). Some researchers have used cross-country data (or international data surveys) to understand how the national patent legislation can affect the choice between patents and secrecy. We focus here on the PACE survey developed by Arundel et al. in 1995 and on the surveys of Japanese and U.S. firms (Pitkethly 2001; Cohen et al. 2002).

The PACE survey was directed to the European Union's 840 largest manufacturing and industrial firms located in Germany, the United Kingdom, Italy, Belgium, the Netherlands, Spain, Denmark, and France. The findings of the PACE report confirm important industry variations regarding the effectiveness of IP protection tools for European firms. As in the case of Levin et al. (1987) and Cohen, Nelson, and Walsh (2000) for the United States, patents play an outstanding role in the pharmaceutical and chemical industry for both product and process inventions. Secrecy is important in protecting process inventions in most industries. Arundel, van de Paal, and Soete (1995) suggest that differences in IP legislation and enforcement can explain why European firms tend to use a different mix of IP tools than U.S. firms. Arundel and Kabla (1998) combine the PACE survey data with data on French firms collected by the French Office of Industrial Studies and Statistics (SESSI). The data are used to investigate differences in patent propensities across industries. As expected, patenting propensities are higher for product innovators (36 percent) than process innovators ( 25 percent). The sectors with the highest patenting propensities are pharmaceuticals and precision instruments; the lowest patenting propensities are found in textiles, regardless of product or process innovators. The surveys also reveal that firms are more likely to rely on patent protection if they export to the United States or Japan.

Cohen et al. (2002) compare results from a survey among 593 Japanese and 826 U.S. firms regarding the importance of patents as appropriation mechanisms. It emerges that slightly more respondents in Japan rated patents as an effective means to protecting innovations than in the United States (38 percent and 36 percent, respectively, for product and 25 percent and 24 percent, respectively, for process innovations). The more striking result is that secrecy is regarded as a much less effective way to protect innovations in Japan than in the United States (26 percent and 51 percent, respectively, for product and 29 percent and 53 percent, respectively, for process innovations). Hence, while in the United States, other appropriation mechanisms, above all secrecy and lead time, are regarded as the most effective ways of protecting innovations, in Japan, patents are equally important as any of the other mechanisms. The authors explain these differences in the importance of patents in Japan and 
the United States by institutional differences in the countries' patent systems. For instance, at the time of the survey, patent laws allowed innovators to apply for a patent early in the innovation process in Japan due to a first-to-file rule of priority (as opposed to the U.S. first-to-invent rule of priority). Also, Japanese patents were subject to "pregrant opposition" while no analogous opposition process existed in the United States. These differences implied that Japanese firms rated patents as a stronger tool to protect their IP. Pitkethly's (2001) survey of patenting Japanese and UK companies also suggests that Japanese companies consider patents as more important a source of technical information than UK companies. ${ }^{17} \mathrm{~A}$ similar result is seen by Cohen et al. (2002), who find that Japanese firms are much more likely to see patents as information sources contributing to the completion of innovation projects and to view patents as an important source of information.

These differences obtained from crosscountry comparisons are interesting. However, the comparison of relatively similar IP systems (especially within the European Union) limits the degree to which such differences can explain observed differences in the choice between formal and informal appropriation mechanisms.

\section{Theory}

In this section, we review theoretical arguments that suggest why and how firms choose between formal and informal IP protection. We concentrate our discussion on patents and secrecy, as these are the main types of formal and informal IP considered in the theoretical literature. It is also true that, in principle, the choice between patents and secrecy involves

17 Pitkethly surveyed in 1994 a nonrandom sample of 211 Japanese and 259 UK companies that have applied for patents. The survey focuses on IP management practices. an explicit and fairly stark trade-off between disclosure and nondisclosure of an inventive idea. In contrast, consider the traditional use of IP in form of copyright for protection of software by protecting its expression in bits and bytes. This use is commonly combined with the use of trade secrecy for the code that exists in a form comprehensible by humans so that, in principle, no trade-off between copyright and secrecy exists. That is, a software program can be both published in machine form under copyright and protected (at least barring considerable effort in reverse engineering) by secrecy. ${ }^{18}$ The same considerations apply to such informal instruments as lead time and complexity-in principle, these can easily be combined with any of the formal mechanisms, so there is no real need to choose. However, in principle, full secrecy rules out the use of the patent instrument for protecting IP, which is why there is a focus on this choice in the theoretical literature.

Table 4 shows schematically the four options available to a firm faced with the decision of whether to patent or maintain an invention secret. Of course, this assumes that firms have a choice. If, for example, the invention does not represent patentable subject matter, the option of obtaining patent protection does not arise. Importantly, the table refers to inventions as the unit of observation, not products. Products often embody a number of inventions, which can be protected by different mechanisms (see section 4 for more discussion). Table 4 also shows that, apart from either patenting or secrecy in the lower-left and upper-right quadrants, respectively, firms may in fact combine secrecy and patenting to protect a given invention (upper-left quadrant) or discard both options (lower-right quadrant). In what

18 The legal situation with respect to reverse engineering of software code is somewhat complex and evolving. See Samuelson and Scotchmer (2002) for a fuller discussion. 
TABLE 4

PAtenting Versus SeCREcy

\begin{tabular}{lll}
\hline \hline & \multicolumn{1}{c}{ Patent } & \multicolumn{1}{c}{ Don't patent } \\
\hline Secrecy & Patent-secrecy combination & Secrecy only \\
Nonsecrecy & Patent only & Disclosure-publishing \\
\hline
\end{tabular}

Source: Graham (2004).

follows, we discuss each of these options in turn, although we focus on the choice on the off-diagonals because that is the most widely modeled.

\subsection{Patent and Secrecy as Substitutes}

Much of the theoretical literature regards a firm's choice between patents and secrecy as mutually exclusive (Friedman, Landes, and Posner 1991). The choice is explained by the inherent trade-off between the benefits from using patents and its costs, relative to relying on secrecy. Benefits and costs are not only a function of the invention that qualifies for patent protection, but also of defensive or offensive strategic considerations taking into account a firm's competitors' behavior. This is hardly surprising in light of the nature of IP, i.e., its value lies in affecting third parties' behavior rather than directly affecting a firm's own inputs into production..$^{19}$

There are differences in the legal protection conferred by patents and secrecy. First, patents are granted only on patent eligible subject matter. The definition differs across jurisdictions. For example, the EPO does not consider computer enabled inventions (software) per se as patent-eligible subject matter whereas the USPTO does. Hence, secrecy is applicable to a much broader

19 A firm's own freedom to operate is ensured by blocking third parties from claiming property rights on a specific invention. range of inventions than patents, as there is no formal subject restriction. ${ }^{20}$ Patentability requires an invention to satisfy the novelty and inventive step thresholds, whereas there is no such requirement for secrecy (even when nondisclosure agreements are used). ${ }^{21}$ This implies that secrecy can protect work in progress, whereas only inventions that have reached a certain stage of development can be patented, as they need to meet these statutory requirements for patentability. Second, if granted, a patent offers 20 years of statutory protection. Secrecy, in contrast, can potentially protect the invention indefinitely. However, an invention that is being kept secret may legally be appropriated by a firm that has independently discovered or

\footnotetext{
${ }^{20}$ Secrecy usually protects commercial information, financial data (e.g., pricing and costing data), business methods, business strategies, business plans, customer/supplier lists, technical designs, drawings, blueprints, maps, negative information (i.e., things that have been tried but did not work), prototypes, formulae, and recipes-for which patent protection would normally not be available.

21 According to Article 39 TRIPS, any "undisclosed information" is protected by secrecy if secrecy is maintained through "reasonable efforts," although the effective protection of trade secrecy varies substantially by jurisdiction. Some jurisdictions may impose additional requirements such as that the information be nontrivial. Contrary to patents, trade secrecy protection does not require an inventive step. It suffices that the undisclosed information has economic value, i.e., a third party would benefit economically if it gained access to the information. Depending on the jurisdiction, trade secrecy may also be protected by unfair competition law, tort law, criminal law, as well as breach of confidence and contractual obligations.
} 
reverse engineered it, whereas the same is not true of a patented invention. ${ }^{22}$

Some technologies are easier to protect with a patent and, once granted, a patent is easier to enforce because the technology is inherently easier to describe and delimit. This factor may affect the willingness of firms to use the patent system. The leading example of the importance of this is the chemicals sector, including pharmaceuticals, where patents protect a specific compound that can be described in a precise chemical formula. This leads to fewer (although not zero) disputes over the exact breadth of the patent and easier notice, in the property rights sense (Bessen and Meurer 2008). The contrast with the information technology sector, where the precise breadth of patent is often unclear, is striking, and is one of the reasons that patents in that sector are generally not used primarily for appropriating the returns to innovation.

Applying for a patent requires direct and indirect financial expenditures. If a patent is granted, it protects an invention only in the jurisdiction in which it was granted. The published patent is visible, however, outside of jurisdictions where the patent is in force. Thus, the invention could be legally imitated and used in jurisdictions where the patent is not in force. Moreover, to keep the patent in force, maintenance fees have to be paid to each patent office that has validated the patent. However, secrecy is also costly because often it is vital that confidentiality agreements are used and the knowledge of the invention is guarded. Keeping innovations

\footnotetext{
${ }^{22}$ The situation is slightly more complicated under a first-to-invent priority system such as prevailed in the United States until 2012. In this case, the firm holding an invention secret could, in principle, file for a patent if another firm filed for a patent on the same invention, provided it could be shown that the later-filing firm invented it first. An "interference" proceeding at the patent office might be the outcome and there is no guarantee that the first firm would win, given the difficulty of establishing priority.
}

secret usually requires considerable effort and active knowledge management in the form of an internal secrecy policy, which may be costly to implement and maintain. For example, firms may rely on the splitting of $R \& D$ into different components across researchers and research labs such that individual pieces of R\&D do not allow a complete understanding and functioning of a given technology. ${ }^{23}$

Both patents and secrecy are expensive to enforce. In the case of patents, enforcement requires active monitoring of potential infringement and the financial resources to engage in litigation. ${ }^{24}$ Enforcement of secrecy will also be costly and may be difficult to achieve in court. ${ }^{25}$ The legal protection of secrecy is also narrower as only

23Zhao (2006) provides empirical evidence that multinational firms tend to split knowledge more if part of the research is executed in countries with weak IP rights protection. A rather low-tech product also illustrates this point: Thomas's English Muffins. A recent U.S. court case suggests that Thomas's splits the recipe of its English Muffins, which is a trade secret, into separate components, such as the basic recipe, the moisture level of the mixture, and the baking process. Reportedly, only seven key employees know all steps required to make the muffins, while all other employees only have knowledge about their specific assigned task in the manufacturing process. This case also serves to illustrate the threat to secrecy that emerges from the movement of personnel, as the court case was triggered by concerns that one of the seven "informed" employees might reveal his knowledge after having accepted a job with the competitor. See New York Times, August 6, 2010.

${ }^{24}$ For example in case of the UK, total costs for the plaintiff and defendant of a court action in a patent case are typically between $£ 1$ and $£ 6$ million (Helmers and McDonagh 2012).

${ }^{25}$ Data on court cases alleging the misappropriation of trade secrets show that in the overwhelming share of cases (former) employees and business partners are accused of misappropriation (Almeling et al. 2010, 2011). This may indicate that proving misappropriation of trade secrets by third parties in court, including misappropriation by competitors, may be very difficult. Moreover, the owner of a trade secret may have little incentive to pursue a case in court if this could lead to more confidential information being revealed during court proceedings. As Neil Wilkoff put it in a recent IPKat blogpost (April 2, 2013), "Whatever the amount of any court judgment for breach, the trade secret smoke is out of the bottle and not even Aladdin will be able to retrieve it." 
TABLE 5

Factors Affecting the Patent-Secrecy Choice

\begin{tabular}{lll}
\hline \hline & \multicolumn{1}{c}{ Patents } & Secrecy \\
\hline Disclosure (codifiable knowledge) & Yes & No \\
Disclosure (tacit knowledge) & No & No \\
Ease of delimiting invention & Yes & Not clear \\
Reverse engineering allowed in general & No & Yes \\
Subject matter & Statutory & Broader \\
Timing & After invention & Work-in-progress \\
Process versus product & Both & Easier for process \\
Length & Twenty years & Longer (potentially) \\
Cost to obtain & Higher & Nonzero \\
Enforcement cost & Expensive & Expensive \\
\hline
\end{tabular}

misappropriation of the invention can be claimed in court. The value of a patent or secrecy depends on the financial capability of the owner to undertake legal action in case of infringement or breach of confidentiality is detected and the likelihood of success of the court case. We summarize these considerations in table 5 .

Second, there is uncertainty involved in the use of both patents and secrecy. With regard to patents, there are three instances where outcomes are uncertain: whether a patent is granted, whether the patent is invalidated postgrant (either by the patent office or a civil court), and whether infringement can be proven-that is, whether it can be shown that an infringing action falls within the valid claims of a patent. In the case of secrecy, the uncertainty concerns mostly whether the invention can be maintained as secret, although the question of whether, for example, breach of confidentiality can be enforced may be also relevant.

The theoretical literature discussed below takes these factors as given and, instead, focuses on specific elements of the patent-secrecy trade-off. In the following subsections, we discuss theoretical models of the patent-secrecy choice, classifying them into models that focus on disclosure, competition for innovation, lead time, and complexity, and the consequences of sequential or cumulative innovation.

\subsubsection{Disclosure}

In principle, once an inventor decides to disclose an invention, he forfeits the option to protect the invention through secrecy. Moreover, the information disclosed in a patent may be only imperfectly protected by the patent simply because infringement has to be detected and enforced through litigation, which may have an uncertain outcome. This suggests that disclosure required by a patent may have an important effect on an inventor's decision to patent or maintain an invention secret. Horstmann, MacDonald, and Slivinski (1985) show that an innovator's propensity to patent falls if patents reveal information to competitors. The model by Horstmann et al., however, does not allow firms to strategically choose the 
amount disclosed through a patent. The seminal model by Anton and Yao (2004) henceforth, AY-in contrast, looks directly at the role of disclosure in a firm's decision to patent. In the model, disclosure has two effects: on the one hand, it helps competitors innovate and on the other, it can be used strategically to transmit information on the innovator's competitive edge to a laggard competitor. We sketch the AY model below, using a general downward-sloping demand function rather than the linear demand function used by AY.

The AY model is a three-stage signaling game with two risk-neutral firms - the innovator, $i$, and the competitor, $j$. In the first stage ("protection and disclosure stage"), the innovator invests in $R \& D$; the outcome is a process innovation allowing the innovator to produce at marginal cost, $c$. The outcome of the investment in R\&D is uncertain: in case of failure, the firm uses the existing technology and produces at a marginal cost $\bar{c}>c$. The R\&D outcome is observed by the innovator but not by the competitor. ${ }^{26}$ The innovator has to decide how to protect his innovation. He has two options: he can either use a patent $(P)$ or can keep the innovation secret $(S)$. Regardless of whether the innovator chooses $P$ or $S$, information on the process innovation leaks, which allows the imitator to replicate the process innovation and produce at marginal cost $s$ (where $s \geq c$ ). That is, $\mathrm{AY}$ assume that disclosure under patenting is the same as under secrecy, with the only difference being that the imitator is liable to damages if he is found to infringe the patent. This is a fairly innocuous assumption, whose relaxation would complicate the model without adding much insight. In the second stage ("infringement-risking imitation stage"), having observed the choice of the innovator of the previous stage, the competitor (who does

\footnotetext{
${ }^{26}$ Encaoua and Lefouili (2005) obtain results similar to AY in a full information set-up.
}

not invest in R\&D) has to choose whether to imitate and risk infringement (if the innovator has chosen $P$ ) or use the existing technology. In the third stage ("competition stage"), the two firms compete as Cournot.

Competition stage. There are three different types of competition regimes, depending on the choices of the innovator and of the competitor in the previous stages of the game. If the innovator has decided to rely on secrecy, the competitor can imitate the innovation at no cost and produce at marginal cost $s$. In this case, the market reduces to pure Cournot competition. If the innovator has obtained a patent, the competitor can imitate and risk infringement or stick with the existing technology. If he uses the existing technology, his marginal cost is $\bar{c}$. Firms compete under Cournot, although the imitator now faces a larger marginal cost, $\bar{c}>s$. If the imitator decides to imitate the patented invention, his marginal cost is $s$, but he is exposed to the risk of being caught infringing the patent. In the model, the imitator is found to infringe the patent with probability $\gamma$. If infringement is found, the imitator has to pay the innovator damages. In the model, these are modeled as royalties on the revenues: $\tau p q_{j}$ where $\tau$ is the royalty rate. Hence, $\gamma \tau=g$ defines the expected infringement damages rate. AY interpret this as an indicator of the strength of the property rights available to the innovator. If $g=1$, then the innovator has full property rights; if $g=0$, he has no property rights in the invention.

Two of the three competition regimes are straight Cournot, with costs $(c, s)$ or $(c, \bar{c})$. Therefore, we focus on the third case, where there is a patent and the imitator risks infringement. In this case, the profits for the imitator, $j$, are equal to the difference between total revenues and total production costs net of expected infringement damages:

$$
\pi_{j}=(p-s) q_{j}-g p q_{j}
$$


The profits for the innovator $i$ can be expressed as the difference between the total revenues and total costs plus the expected damages from the infringement of the patent:

$$
\pi_{i}=(p-c) q_{i}+g p q_{j}
$$

We assume a monotonic demand function $p=F(Q)=F\left(q_{i}+q_{j}\right)$ with $F^{\prime}<0$. From this we compute best response functions for the innovator and the imitator, and solve for the equilibrium output choices as a function of the degree of disclosure and the strength of property rights.

$$
\begin{aligned}
& q_{j}^{*}=\frac{1}{-F^{\prime}\left(Q^{*}\right)}\left[F\left(Q^{*}\right)-\frac{s}{1-g}\right] \\
& q_{i}^{*}=\frac{1}{-F^{\prime}\left(Q^{*}\right)}\left[F\left(Q^{*}\right)-c\right]-g q_{j}^{*} \\
& =\frac{1}{-F^{\prime}\left(Q^{*}\right)}\left[(1-g) F\left(Q^{*}\right)-c+\frac{g s}{(1-g)}\right]
\end{aligned}
$$

With some tedious manipulation, we can use equation (3) to show that the weaker property rights protection is (lower $g$ ), the more the imitator produces and, conversely, as $g$ increases. ${ }^{27}$ One can also show that as $s$ increases relative to $c$ (less disclosure), the ratio of the innovator output to imitator output grows. In passing, note that $j$ will not produce unless the market price covers his marginal cost and the royalties he has to pay $\left[p^{*}(1-g)>s\right]$.

\footnotetext{
27 There are some auxiliary conditions: $F^{\prime}$ has to be sufficiently small and positive (or zero, as in the case of linear demand), and it has to be profitable for the imitator to produce.
}

The expected profits in equilibrium are:

(4) $\pi_{j}=\frac{1}{-F^{\prime}\left(Q^{*}\right)}$

$$
\begin{gathered}
\times\left[(1-g) p^{* 2}+\frac{s^{2}}{1-g}-2 s p^{*}\right] \\
\pi_{i}=\frac{1}{-F^{\prime}\left(Q^{*}\right)} \\
\times\left[p^{* 2}+g c p^{*}+c\left(c-\frac{g s}{1-g}\right)-2 c p^{*}\right]
\end{gathered}
$$

Assuming a linear demand function as in AY, one can use equation (4) to show the trade-off the innovator faces when choosing the optimal degree of disclosure. On the one hand, disclosing too much information (lower $s$ ) reduces profits, as the imitator can now more easily replicate the process innovation. On the other, the profits of the innovator increase (and those of the imitator fall) if the imitator infers that the innovator has lower costs (smaller $s$ ).

Infringement-risking imitation stage. The competitor has to choose whether to imitate (risking infringement) or use the existing technology. He can observe whether the process innovation has been patented and the degree of disclosure. He cannot observe the marginal cost of the innovator and, therefore, is not fully aware of the extent of the competitive advantage conferred by the innovation. If the innovator has not patented, the imitator can use the disclosed knowledge and produce at cost $s$ without infringement risk. If the innovator has patented, the imitator has two alternatives: he can imitate and risk infringement or use the existing technology.

Suppose the innovator chooses to patent and discloses $s$. If the competitor does not imitate, he faces a cost disadvantage of $\bar{c}$ versus $c$, and profits equal to $-\left(p_{N}-\bar{c}\right)^{2} / F^{\prime}\left(Q_{N}\right)$, 
where $N$ denotes the price and quantity with no imitation. If he decides to imitate, the cost disadvantage is $s$ versus $c$, but there is the risk of having to pay damages. Using equation (4), the expected payoffs for the competitor under the different scenarios are:

$$
\text { (5) } \frac{\left(p_{N}-c\right)^{2}}{F^{\prime}\left(Q_{N}\right)}><\frac{(1-g)\left(p_{I}-s /(1-g)\right)^{2}}{F^{\prime}\left(Q_{I}\right)}
$$

The equality in equation (5) identifies an equal payoff line (EPL) in the $(i, j)$ marginal cost space along which the expected payoffs are the same and, therefore, the competitor is indifferent between imitating and nonimitating. Above this line, (where $s$ is closer to $\bar{c}$, that is, disclosure is weak), the competitor chooses not to imitate, while below it, he chooses to imitate. The intersection between the EPL and the line where $c=s$ (i.e., the $45^{\circ}$ line) gives the cut-off level of the inferred costs above which the competitor has no incentive to imitate. In the case of linear demand with $p=\alpha-\beta Q$, AY show that this point is given by the following expression:

(6) $c^{*}(g, \alpha, \bar{c})=\frac{2 c+\alpha[(1-g) h(g)-1]}{1+(1+g) h(g)}$

where $h(g)=3 /[(3-g) \sqrt{1-g}]$.

So the competitor will imitate when, given the expected damages implied by $g$, the cost disadvantage of using the new technology over the inferred cost of the innovator is smaller than the cost disadvantage of using the existing technology compared to the inferred cost of the innovator.

Protection and disclosure stage. The innovator decides whether to use a patent or secrecy and how much to disclose. The equilibrium involves three distinct regions: 1) a region where an innovator with high marginal costs and a small invention prefers to patent the invention and fully disclose the technical knowledge; 2 ) a region where the innovator with a medium size invention prefers to patent and partially disclose the invention; and 3) a region where the innovator with a large invention chooses secrecy and partially discloses the knowledge.

If the innovation is relatively small $\left(c>c^{*}\right)$, the cost reduction of $s$ over $c$ is insufficient to justify the risk of infringing a patent and therefore the competitor has no incentive to imitate. In this case, the innovator has a strong incentive to patent and to disclose fully to signal low cost, which has a positive impact on his expected profits. AY show that the result holds even under a weak property rights regime. In addition, as $g \rightarrow 1$ (strong property rights), the cutoff $c^{*}$ tends toward zero and the innovator will always patent and disclose fully.

For $c<c^{*}$, the competitor finds imitation attractive and, therefore, the innovator no longer has an incentive to disclose fully. Instead, the innovator faces a trade-off between signaling low costs (and obtaining larger damage payments) and transferring knowledge to a competitor. In other words, it is worth signaling low costs through disclosure and to obtain damages if the patent is infringed. So the innovator will now disclose partially.

For large innovations, however, the tradeoff to signaling via partial disclosure and patenting becomes less attractive. The innovator has two sources of profits under imitation: revenues from damages if the patent is infringed and profits. As the innovator's marginal cost of production falls (i.e., the innovation gets larger), the innovator faces the same trade-off as in the medium innovation region. On the one hand, the innovator may be induced to disclose more knowledge to signal low cost. On the other, lower marginal cost (for a given amount of disclosure) implies that it can produce more than its competitor. The competitor faces two opposite forces as 
well: on the one hand, lower marginal cost of the innovator implies lower profits for the competitor. On the other, if the innovator discloses more, the competitor's marginal costs fall. AY show that in equilibrium, a large innovation leads the innovator to rely more strongly on the cost advantage and less on expected damages. For $g$ sufficiently small and $c$ sufficiently large, the cost-advantage effect dominates. In equilibrium, giving up property rights signals a large innovation and permits less disclosure of valuable enabling knowledge.

To support this counterintuitive result empirically, AY point to the example of the Ford Motor Company in 1913, after introducing the moving assembly line process. Ford encouraged wide disclosure of this innovation, which was not patent protected, but according to Hounshell (1984), the disclosure was insufficient to allow full imitation. The basic rationale was that Ford wanted to signal to competitors that it had extremely low production costs, in order to discourage them. Although an interesting example, it is not clear that patenting was even an option in this case, as the innovation was essentially organizational. But it does capture the motivation that the AY model relies on. As we will see later, the general conclusions of the AY model are overturned if the innovator is threatened by a rival innovator who might patent first. In this example, the (partial) lack of patentability and the first-to-invent system that prevailed then would probably have discouraged patenting by a rival anyway.

Zaby (2010) arrives at the same conclusion as AY, that is, important innovations are not patented, whereas the less important ones are. Zaby analyzes the patenting decision of an innovator who is aware that patenting an invention involves disclosure of knowledge, which may enable a competitor to imitate its invention. The key differences from AY are that: a) there is no asymmetric information on the size of the innovation; b) the innovator cannot choose the amount of technical knowledge to disclose with a patent because Zaby assumes that patenting is always associated with full disclosure while secrecy is not; and c) competition is Bertrand with different qualities rather than Cournot. In her asymmetric duopoly model, one firm is a successful inventor while the second firm is not, but may eventually develop the capability of making a closely related invention. The strategic interactions between the two firms are modeled as a three-stage game where in the first stage, the innovator has to decide whether to patent or not. In the second stage, both firms choose their qualities, with firm two restricted to a region that is not covered by the patent, and in the last stage, they compete in prices. While a patent may protect the firm's invention, the firm may run two additional risks: first, a patent requires the full disclosure of the protected invention; second, the competitor may still enter the market with a noninfringing product, as the patent cannot cover all possible product qualities.

Heger and Zaby (2013) use a simplified version of the Zaby (2010) model to look at the role of disclosure in determining a company's choice between patenting and secrecy. The model is based on Salop's circle model (Salop 1979), where firms choose a location in a vertically differentiated product circle. There is a single innovator that can choose to patent to broaden the product space he occupies. All other firms decide whether to enter the market, taking into account the innovator's choice. All firms face some fixed market entry costs that decline with more disclosure. Hence, in this model, the innovator trades off the exclusionary effect a patent has on competition with its disclosure effect, which promotes entry and hence, competition. Since this trade-off varies across companies, the model implies that patenting propensities differ across firms because the disclosure and exclusion effects of a patent differ. 


\subsubsection{Competition for Innovation}

The discussion on the choice between secrecy and patenting has, up to now, focused on the interaction between a single innovator and one or several imitators. This excludes the possibility of simultaneous discovery. Lemley (2012) provides ample anecdotal evidence for the widespread occurrence of such simultaneous discovery, i.e., a situation in which independent researchers produce (almost) simultaneous inventions. The examples show that well-known, disruptive inventions such as the steam engine, the telegraph, the sewing machine, the telephone, and the light bulb, were not the output of individual genius, despite widely held beliefs. Instead, they were the outcome of cumulative research and experimentation where different inventors followed very similar leads at the same time. In all the historic examples provided by Lemley, the successful inventor obtained a patent on the invention, which in most cases produced considerable income for the inventor. In contrast, the other inventors working simultaneously on the same or a similar invention came away empty-handed. Lemley (2012: 755), therefore, argues that "[ $t]$ he patent isn't a carrot so much as a stick with which to threaten the slow." That is, patents offer incentives to innovate not so much because they offer a reward in the form of a patent, but because patents punish those inventors that invest in research but fail to obtain the patent. Hence, in a setting with simultaneous inventions, the decision whether to patent or maintain an invention secret is dominated by the concern over a competitor obtaining a patent first, which overturns the AY result above.

Kultti, Takalo, and Toikka (2006) makes the fairly obvious point that when there is a possibility of simultaneous invention, even when secrecy offers stronger protection, firms will prefer to patent to prevent their competitors from patenting the same invention. They consider a duopoly where firms can simultaneously develop the same invention and hence a patent race emerges. The innovator will be willing to patent to gain some competitive advantage if there is a high probability that the competitor develops the same invention. When there is a strong likelihood of simultaneous invention, patenting takes on a defensive role: now the choice is not between patenting and secrecy, but between patenting and allowing a competitor to patent. Since the inventor that obtained the patent always earns higher profits, there is a strong incentive to patent. ${ }^{28}$ This type of result has similarities with the older patent race models where, in a "winner-take-all race," firms compete in research (Wright 1983; Gilbert and Newbery 1982). Kultti, Takalo, and Toikka's main result that patenting is preferred remains true even if patenting per se offers slightly less chances of protection than secrecy. However, this result only holds if the protection offered by the patent system is above a certain threshold: if the protection from patenting falls (say due to weak enforcement), then at some point secrecy will be preferred.

The main argument of the paper is given in a simple model. Two firms invest in R\&D, which results either in an innovation (with probability $q$ ) or not (with probability $1-q$ ). Suppose that the innovation can be protected only by secrecy. Secrecy is effective with probability $\alpha$. If only one firm succeeds in its R\&D, it earns monopoly profits. If both firms succeed, each firm earns duopoly profits $\pi^{D}<\pi^{M} / 2$. The firms can choose their success probability by paying $c(q)=R q^{2} / 2$. If firm one chooses $q_{1}$ and firm two chooses

\footnotetext{
28 This incentive is also affected by the legal situation surrounding "prior-user rights." These are the rights given to the original innovator if he relied on secrecy, but a subsequent imitator obtained a patent on the innovation. Generally, such rights are limited, although some jurisdictions allow them in certain cases (notably the United States, for business methods).
} 
$q_{2}$, the expected profits for firm one are equal to:

$$
q_{1}\left(1-q_{2}\right) \alpha \pi^{M}+q_{1} q_{2} \alpha \pi^{D}-R q_{1}^{2} / 2 .
$$

If we introduce the possibility that a firm can patent, now firm one has to choose how to protect its innovation before it learns whether the competitor has successfully innovated. It has two options: it can either patent or use secrecy. If both firms are successful and file for a patent, each firm obtains the patent with probability one half. The strength of the patent $\alpha_{p}$ is defined as the probability that a patent holder can exclude the competitor from using the invention. Using equation (7), it is easy to show that patenting is the dominant strategy, even if the patent offers weaker protection than secrecy. The intuition is that if the probability that the second inventor can innovate is large, the innovator may prefer to patent to make sure that the other inventor cannot patent.

Kultti, Takalo, and Toikka (2007) extends the model to an infinite horizon discrete time model with a continuum of inventors and ideas. The results are similar-if patent strength is strong, all firms patent and if patent strength is weak, all firms choose secrecy. However, there is an intermediate range of patent strength where some firms choose to patent and others choose secrecy. They then go on to characterize the optimal patent strength from a welfare perspective. While intuitive, the model ignores the possibility that firms might torpedo each other through strategic disclosure in the form of defensive publications, which would jeopardize the possibility to patent the resulting invention. If such strategic disclosure is possible, this would give rise to strategic interaction in the form of private arrangements in which favorable exclusive bilateral licensing agreements are negotiated, which could undo the incentives for the race (see discussion in section 3.3 below).
Mosel (2011) revisits the results obtained by AY discussed previously by extending the Kultti et al. framework to allow for heterogeneity in the "quality" of innovations. The main differences from AY are that (a) both companies conduct $\mathrm{R} \& \mathrm{D}$, (b) patenting is costly, and (c) there is full disclosure if a firm decides to patent. ${ }^{29}$ This model produces results that are the reverse of those in AY: small innovations are not patented (because of the filing costs) while large innovations always are (because the benefit of patenting first relative to the competitor outweighs the patenting costs). This result seems to accord much better with reality (see sections 2 and 4 ), although, empirically, a more important determinant of the choice of secrecy over patenting may be the ability to keep the invention secret. The model allows such variability via a single parameter, but the parameter is held constant in the static analysis.

\subsubsection{Lead Time and Complexity}

Many of the firm surveys that ask about the use of methods to appropriate the returns to $R \& D$ and innovation find that firms rate lead time (the first mover advantage) and complexity at least as, if not more important, than patenting for protecting their innovations. The discussion so far attributed to disclosure the decisive role in a company's decision whether to protect an invention through patenting or secrecy, although the work by Zaby (2010) hinted at the possibility that a technological lead might play a role in the decision, and a number of models show that when this lead is large, the inventor may prefer not to patent and use secrecy. Patents will be preferred by the inventor only when its technological lead is moderate.

\footnotetext{
${ }^{29}$ The model also allows for the possibility that patent applications get rejected, which is assumed to be a function of the "quality" of an innovation and a patent renewal decision. But these features are not crucial for the main results of the model.
} 
Schneider (2008) studies a model similar to Zaby's model, but where the form of competition is left unspecified, in order to allow for a full range of duopoly profits. He assumes that there is one lead innovator and one potential follower innovator. If the follower innovates, the two products compete. The follower only tries to innovate if he expects to make profits, which depends on the cost of R\&D and nature of competition. This gives rise to the possibility that the lead innovator chooses to keep an invention secret in order to prevent disclosure, which will raise the cost of the follower's R\&D. Schneider's model suggests that this is only rational "when the speed of discovery of the subsequent invention is high [for the lead innovator], relative to the competitor's" (Schneider 2008: 1349). In other words, the lead innovator has the ability to generate a series of new products and secrecy prevents a competitor entering the race. This conclusion is essentially the same as that in the previously cited Zaby (2010). Both reach the conclusion that firms with a large technological lead over their competitors may prefer secrecy to patenting.

There is a small literature that explores the role of strategic interaction among imitators in influencing the innovator's incentives to patent. In this literature, an innovator can strategically delay entry by imitators, i.e., create lead time, by providing incentives for imitators to free-ride on each other's imitation efforts. This creates a delay between innovation and imitation even in the absence of patents. The decision to patent, therefore, depends on whether profits from secrecy exploiting the strategically created lead time exceed those obtained from patenting. In the model by Henry and Ruiz-Aliseda (2012), innovators achieve lead time by investing in technology that protects an invention, such as product complexity. In Henry and Ponce (2011), innovators use licensing to potential imitators strategically to create lead time. In Anton and Yao (1994), an innovator also exploits (the threat of) licensing to appropriate returns to his invention. But the mechanism is different because this model assumes imperfect information and hence the need to disclose information to attract licensees. We discuss each of these models in turn.

Henry and Ruiz-Aliseda (2012) allow an innovator to invest in making it harder for potential competitors to imitate an innovation via reverse engineering. If imitation is costly, imitators also have to decide whether to protect the imitation from copying because, if the imitator fails to patent, all other imitators can imitate at zero costs. Henry and Ruiz-Aliseda (2012) show that, if imitation costs are sufficiently large, imitators will delay reverse engineering in the hope that another imitator pays the costs first, which would then allow them to imitate without incurring the costs associated with overcoming copy protection. Hence, innovators may choose secrecy over patents for technologies where secrecy can be accompanied by product complexity so that reverse engineering can be made very costly. Henry and Ponce (2011) use a similar model of competition among imitators to show that innovators can strategically create lead time over their competitors without using a patent. They analyze a setup in which an inventor can sell specific knowledge on an invention to potential imitators and these potential imitators have the choice between costly imitation and acquisition of the knowledge. In equilibrium, inventors choose to sell their technology in a way that allows acquiring firms to resell the knowledge to other firms. As a result, once the first imitator has acquired the knowledge and entered the market, he will compete with the innovator in the market for knowledge and drive prices for the knowledge to zero. This is, nevertheless, optimal for the inventor because potential imitators do not immediately enter the market, but wait in the hope that another firm enters first and drives down the price of the required knowledge. This produces a situation in which the inventor 
enjoys a temporary monopoly position without recourse to a patent.

The Henry-Ponce model implies that the more tradable knowledge is, holding the patent term life constant, the more likely firms are to rely on secrecy rather than patents (assuming patenting is more expensive than maintaining an invention secret). The intuition behind this is that the certain length of the protection granted by a patent has to outweigh the relative costs associated with patents because inventors can also reap monopoly profits from the delayed entry of imitators.

The mechanisms used by an inventor to appropriate returns from innovating in Henry and Ponce (2011) are fundamentally different from the seminal Anton and Yao (1994) model. In Anton and Yao (1994), a financially constrained inventor sells an invention to two companies, which invent it themselves with some probability. They assume that the invention cannot be protected by a patent and that the companies cannot observe the quality of the invention ex ante. Anton and Yao show that in equilibrium, the inventor first fully reveals the invention to the buyer before signing a contract. Although the buyer could use the disclosed invention without compensating the inventor, the buyer will offer the inventor a contract ex post with a strictly positive payoff. This is optimal, from the buyer's perspective, to keep the inventor from also selling the invention to its competitor. The model, therefore, shows how an inventor can obtain rents without recourse to patent protection in a setting characterized by incomplete information, due to the threat of competition among the buyers. While these models offer plausible ways for companies to appropriate returns to innovation without patents, it appears, however, that in practice firms find patents convenient when constructing knowledge contracts (see also sections 2 and 4).

\subsubsection{Cumulative or Sequential Innovation}

The aforementioned models of secrecy and patenting assume that innovations are discrete and use a one invention (or one innovation)-one patent model. The innovation usually takes the form of a process innovation that lowers production costs. However, in reality innovations are often complex, involving many inventions covered by patents and also cumulative (or sequential), i.e., inventors build on the innovations of others. At a very basic level, in industries where innovation is cumulative, secrecy can lead to duplication of efforts. For example, Erkal (2005) obtains this result in a model with two sequential innovations (each one involving a race between two innovators). The key assumption of the model is that, if the first innovator relies on secrecy, then the subsequent innovators do not have as much knowledge, which not surprisingly does lead to duplication of efforts. Thus, in cases where sequential innovation is important and there are several innovators, she argues that it may be worthwhile increasing the breadth of patent protection (since this will encourage the use of patents and associated disclosure).

Scotchmer and Green (1990) were the first to look at the question of whether the inventor of a "weak" or "partial" invention that provides information for subsequent research will choose to patent it or keep it secret, and whether the novelty requirement should be weak to encourage disclosure of such an invention. They conclude that such a requirement will not help much because the firm can always choose not to patent, even if it is possible. They also show that the first invention is more likely to be patented under a first-to-file system (which is now the norm around the world) than under a first-to-invent system. However, neither of these systems is first best, a fact that they have also explored in other work (Green and Scotchmer 1995). 
Ponce (2011) lays out a model that is similar to Scotchmer and Green's, but adds the assumption that disclosure (patenting) creates prior art, which increases the difficulty of patenting subsequent inventions. In Ponce's model, the first innovator trades off the effect disclosure has on lowering the probability that the rival innovator patents with the effect that the disclosed information has in helping the rival to successfully innovate. When disclosure has little effect on the probability of obtaining subsequent inventions, lowering the novelty standard for patenting increases disclosure, whereas when disclosure strongly affects subsequent innovation, lowering the standard leads to more use of secrecy. Deriving welfare effects for the choice of patentability standard is complex, but generally follows from these observations.

Bhattachaya and Guriev (2006) look at a different situation: instead of sequential invention, they consider sequential R\&D, where $\mathrm{R} \& \mathrm{D}$ is split between companies that perform $\mathrm{R}$ (esearch) and $\mathrm{D}$ (evelopment) separately. In the model, there is a single inventor and two companies that develop the invention into a marketable innovation. The existence of two developers is a key difference from the Anton and Yao (1994) model discussed, where the equilibrium result has a single firm developing the invention. In Bhattachaya and Guriev's model, the inventor comes up with an invention that he then licenses to a developer. Developers produce innovations using either the licensed invention or whatever information about the invention they can obtain through a patent publication or disclosure during licensing negotiations. The information on the invention, as well as the development effort, produce with some likelihood a marketable innovation. If only one developer succeeds in obtaining an innovation, he acts as a monopolist in the product market, whereas if both developers succeed, they compete under Bertrand. The inventor has the choice to patent or to maintain his invention secret. Patenting discloses information to both developers. If the invention is patented, in equilibrium, an exclusive licensing contract with one developer is signed. If the invention is protected through secrecy, in principle, no information about the invention leaks. Information is only transmitted by the inventor to negotiate a licensing agreement. Moreover, if secrecy is used to protect the invention, Bhattachaya and Guriev (2006) assume that the inventor could license the invention to one developer and then subsequently license it opportunistically to the second developer, too. Even if the second developer did not acquire a license, he could use the information obtained during the licensing negotiations to innovate. To avoid this opportunistic behavior, developers optimally offer the inventor a contract that gives the inventor a share of sales.

This contract has the drawback that it lowers the optimal effort exerted by the developer, since he loses a share of his profits to the inventor. Since an inventor can move from secrecy to patenting but not vice versa, secrecy has to offer at least the same payoff as patenting to be optimal. The trade-off that emerges is that secrecy reduces information leakage but at the same time the royalty rate reduces the developers' incentive to invest in development which lowers expected revenues. Bhattachaya and Guriev show that this is the case for sufficiently large disclosure and a valuable invention. The optimal share of revenues paid to the inventor decreases in disclosure (lower return from opportunistic behavior) and the value of the invention (higher expected revenue). Since a lower share increases the incentives for the developer to exert effort and to produce a successful innovation, the payoff for the inventor increases. This result-secrecy is preferred for more valuable and less codifiable inventions-is reminiscent of the AY model 
discussed earlier. However, the mechanisms are fundamentally different.

\subsection{Combined Patent-Secrecy Strategy}

While we have described the choice between patenting and secrecy as a mutually exclusive decision, the upper-left quadrant of table 4 suggests the possibility that formal and informal methods may in fact be combined to protect an invention.

Arora (1997), for example, documents the early days of the organic chemical industry which provide an example of a situation in which firms resorted to both secrecy and patenting to protect innovations. Arora argues that certain chemical innovations were composed of tacit elements, notably the specific combination of different compounds, which were protected by secrecy, and codified knowledge, i.e., individual compounds that were protected by patents. Arora argues, more generally, that knowledge based on "inductive and empiricist procedures" is hard to protect through patents because this type of knowledge is hard to codify and the corresponding claims would have to be narrow which would disclose a great deal of information. Hence, according to Arora, for such inventions firms prefer to patent the codified aspects and to keep the remainder secret. Even in easily codifiable technologies, such as chemical compounds, the best practices of producing a compound may be kept secret, ${ }^{30}$ which suggests that patents and secrecy can act as complements. This also explains why companies in the pharmaceutical industry commonly report relying heavily on both patents and secrecy (Cohen, Nelson, and Walsh 2000, tables 1 and 2).

\footnotetext{
${ }^{30}$ However, in the United States before the 2012 America Invents Act, patentees were required to disclose the best mode for practicing the patented invention according to the Patent Act of 1952 (for more discussion see Love and Seaman 2012).
}

Graham (2004) studies the case where firms combine patenting and secrecy by staging the revelation of information, keeping the codified part of an invention secret while preserving the option to obtain patent protection in the future. He observes that, in the U.S. patent system prior to 1999, patent applications remained secret until the patent issued. By using a continuation, continuationin-part, or a division, assignees were thus able to keep a pending patent application secret for an extended period of time, while maintaining the early priority. In this way, firms were able to effectively combine the benefits of patent protection with trade secrecy and to avoid the trade-off between patent protection and disclosure. Prior to 1995, when the term of the patent was seventeen years from the grant date, rather than twenty years from the application date, there was little cost in terms of length of patent term to this strategy. Graham suggests that the combination of secrecy and patenting through continuation was particularly interesting to firms that had a first-mover advantage in new technological fields in which the incumbents were threatened by entry that could displace the incumbent's technology. However, if lead time is important, Graham argues that firms were less likely to use secrecy and continuation, due to the fact that lead time and secrecy are substitutes. Hegde, Mowery, and Graham (2009) show that firms may still combine secrecy with patenting, to some extent, because continuations still offer the possibility to alter individual claims thereby effectively extending secrecy with regard to specific claims.

Although the available anecdotal evidence suggests that firms indeed combine secrecy with patenting, there are no theoretical models that explore this possibility and the incentives to do so in more detail. Especially the possibility to rely on patents and secrecy at different stages of the research and development process of an innovation might 
offer an interesting avenue for further research.

\subsection{No Patent, No Secrecy-Disclosure}

The final cell of table 4 contains the case where firms choose to simply disclose an invention, for example, in the form of a defensive publication, without having recourse to patent protection.

In contrast to secrecy, defensive publications still guarantee a firm's freedomto-operate and de facto secrecy may even be maintained as the information that is revealed can be restricted or substantially disguised. Defensive publications may be used strategically by firms to influence the state of prior art relevant to competitors' patent applications (Lichtman, Baker, and Kraus 2000; Baker and Mezzetti 2005; Bar 2006). Hence, disclosing previously unknown information to the public can raise the inventive step threshold, jeopardizing competitors' patent applications. Ponce (2007) considers this type of voluntary disclosure in an environment with two innovators who have to choose whether to patent or not in a sequential fashion. The first innovator who patents may face the risk of being imitated. However, the use of secrecy is associated with two additional threats: duplication (when the second innovator develops a similar invention) and exclusion (occurring when an imitator obtains a patent for a similar innovation). In this environment, the first innovator may prefer secrecy if the protection it can get from secrecy is larger than the protection offered by a patent net of the patenting costs. Still, a firm that opts for secrecy will want to disclose knowledge, as it may stop the second innovator from developing the same innovation and patenting it. If so, in equilibrium, the first innovator discloses a sufficiently large amount of information such that the second innovator has no incentive to patent. In this type of equilibrium, where patent protection is weak and product market competition is not too intense, both innovators opt for secrecy, but there may be still disclosure of technical knowledge.

Raising the prior art bar may not be the only function of strategic disclosure. Gill (2008) offers a model in which an innovator that has a lead over its competitor uses disclosure to persuade the competitor to leave the patent race. Gill's model has two stages in which innovators invest in an R\&D project. The leader obtains an intermediate research outcome first and has to decide whether to invest further to turn it into a marketable innovation. The innovator can choose to disclose the intermediate research results (but not the amount of disclosure). This has two effects in the model: on the one hand, disclosure offers useful knowledge to the competitor; on the other hand, it informs the follower about the leader's commitment to the research project. When the latter effect outweighs the former, disclosure makes the follower quit the patent race after the first stage. In Gill's model, the leader only discloses if he continues investing in the R\&D project because disclosure is costly. Disclosure then occurs only when development costs in the second stage are sufficiently large. The intuition for this is simple. If development costs are high, the innovator has an incentive to abandon the project himself unless chances to win the race are sufficiently high. Disclosure helps increasing the chances by providing a credible signal to the follower of commitment to staying in the race, thereby pushing the follower out of the race. Perhaps more interestingly, for intermediate development costs, the model suggests that lead time itself is sufficient to push the follower out of the race, because the follower still believes the leader invests in the secondstage development. Hence, the leader does not need to disclose to drive out the follower, although the option to disclose is crucial for this effect to work.

Anton and Yao (2008) look at the situation in which sellers waive the signing of 
confidentiality agreements when they negotiate the sale of innovation protected by secrecy. ${ }^{31}$ This counterintuitive behavior, voluntarily foregoing the ability to enforce secrecy, can be optimal to attract buyers who have incomplete information on the innovation on offer. Anton and Yao (2008) show that if buyers have incomplete information on the innovation on sale, waiving trade secrecy is optimal for sellers to attract potential buyers as it eliminates the threat of ex post litigation for buyers if they fail to acquire the innovation. While the model offers an explanation for why innovators may choose to disclose an invention that could be protected by trade secrecy and a nondisclosure agreement, the innovator would strictly benefit from using a registered IP right, such as a patent, if he were able to do so. Hence, the model applies to a setting in which an innovator chooses between informal IP protection in the form of trade secrecy and no IP protection.

The open source software sector provides an example of an entire sector that is based on the absence of patenting and secrecy. However, this does not mean that IP protection is foregone completely in this sector. Frequently, various forms of copyright protection accompanied by a General Public License (GPL) are used to ensure that the particular software in question remains open.

Gambardella and Hall (2006) study the general phenomenon of knowledge production in an open (no patent, no secrecy) environment. They show that an equilibrium

\footnotetext{
${ }^{31}$ Confidentiality agreements are often considered necessary to claim misappropriation of proprietary information in contract negotiations. For example, in a recent New York court case, Edelman v. Starwood Capital Group, LLC (NY Slip Op. 09309), investor Edelman failed in his claim for misappropriation of confidential information against investor Starwood LLC, despite having expressly marked the documents provided to Starwood during their failed business negotiations as confidential. The court pointed out that, to obtain trade secrecy protection in this context, Edelman would have had to sign a confidentiality agreement with Starwood.
}

with free sharing of knowledge and no IP protection can exist, but that such an equilibrium is unstable against a defector who chooses to privatize his knowledge (this case is effectively an example of Olson's (1971) Logic of Collective Action). They show that such defection becomes more probable as the number of knowledge producers grows or the value of a particular participant's addition to knowledge rises. Therefore, without some kind of coordination, production of the public knowledge good (science or research software or database) can be suboptimal. The authors show that if "lead" researchers (or "lead" programmers) are able to establish a norm of contribution to the public good, a better outcome can be achieved, and that a GPL is a possible such mechanism. They give a small example of the breakdown of a no-IP equilibrium based on the observed privatization of econometric software production.

\subsection{The Life Cycle of Firms and Industry}

The use of patents for the appropriation of returns to investment in innovation appears to evolve as firms and industries mature. History is replete with examples of new technologies that developed without patents and with considerable sharing of knowledge, such as textile looms (Foray and Hilaire Perez 2006), the Cleveland (UK) iron industry over the period 1850-75 (Allen 1983), and Cornish pumping equipment (Nuvolari 2004). To some extent, a modern example is the software industry in the U.S., which relied heavily on secrecy and copyright until a series of legal decisions in the mid-1990s rendered software patentable..$^{32}$ This example illustrates that after the initial growth of a new technology and industry, a constituency of successful firms develops that wishes to protect their technology via patents.

\footnotetext{
32 Of course, the ultimate causal source for these events was not the courts, but the firms in the industry (including the largest, IBM) who sued the Patent Office when their patent applications were rejected.
} 
Such a constituency will sue to expand patentable subject matter if their technology is not already included, and in any case will transition the sector from an open knowledge-sharing one to one where IP is more protected, as described by Gambardella and Hall (2006).

Boldrin and Levine (2013) make a similar argument, emphasizing that firms switch to using (that is, enforcing) patents when the industry matures in which they operate and demand stagnates. This argument follows the "industry shakeout" literature pioneered by Jovanovich and MacDonald (1994) and Klepper (1996). In the Jovanovic and MacDonald (1994) model, firms in an industry compete to market an exogenous invention. Firms enter into the market to turn the invention (with some exogenously fixed) probability into an innovation. The invention is refined at a later stage, offering firms that had innovated before the opportunity to innovate again. New firms can keep entering during that process and attempt to innovate. Since the innovation lowers marginal production costs, firms that innovate increase output. As a result prices fall. As output expands and prices fall, firms that failed to innovate exit. The model produces a shakeout of companies, i.e., a sudden exit of a large number of firms, if price falls fast. This can occur either because innovating creates a large drop in marginal costs, or because of a high likelihood of innovation. Klepper's (1996) model allows firms to generate both product and process innovations. Process innovation reduces average costs. Because of increasing returns to process innovation, larger firms have more incentives to invest in process innovation. This implies that earlier incumbents have a cost advantage over entrants. Entrants may still find it profitable to enter the market if profits from their product innovation are sufficiently large. However, as companies' output grows, prices fall to such a low level that entry ceases. In the model, firms carry out different types of product innovation, which means as entry stops, fewer product innovations are available in the market. Because of this, as well as increasing returns to process innovation, process innovation expands at the expense of product innovation. The market is left with fewer and larger companies that produce a smaller range and number of new products.

Boldrin and Levine (2013) argue that industries are characterized by the absence of patents during the innovation phases. Following a shakeout, the remaining firms begin to prefer patents over alternative mechanisms to secure their oligopoly rents. They suggest that patterns observed in patent litigation in the United States confirm this hypothesis. Notably, companies that see decline in their revenue shares of a market, such as Texas Instruments, begin to rely on patent litigation to extract rents from entrants.

Although true, the fact that declining firms turn to enforcing their patents is not necessarily always a negative thing. In principle, a bankrupt or money-losing firm normally attempts to capture as much salvage value as it can from the assets it owns. The fact that firms can do this if they fail helps them to raise money from investors ex ante, since the investors stand to lose less in the event of failure than if the assets were simply abandoned. To the extent that patentable technology has salvage value and serves as an asset to the firm, it is appropriate that the exiting firm try to realize that value via enforcement or sale to another entity that is able to realize the value. ${ }^{33}$

\footnotetext{
${ }^{33}$ Much of the critique of this kind of activity is based on the facts that the patents thus enforced may be of low quality and may rely on a kind of holdup strategy where it is cheaper for the accused infringer to settle, rather than to test the patent's validity (e.g., Lemley and Shapiro 2005). That is, in principle it is appropriate for a nonproducing entity to realize value from a patent portfolio, but various features of current patent administration and legal enforcement make such strategies more of a tax on innovation than an incentive for innovative entry.
} 


\section{Empirical Evidence}

The surveys reviewed in section 2 gathered a large amount of information on companies' perceptions on the importance of the different appropriation mechanisms and their self-reported use. The theoretical models discussed in the preceding section look at specific aspects of the trade-off that companies face in choosing a mechanism to appropriate returns to innovation. This section discusses the empirical literature that analyzes the determinants of firms' choices of the different appropriation mechanisms and the corresponding outcomes. In very few cases, this literature attempts to relate their results to the theoretical literature discussed earlier, but for the most part the empirical literature has evolved separately, partly due to lack of the appropriate data, as we discuss below.

\subsection{Registered IP and Secrecy as Substitutes}

The empirical literature has focused overwhelmingly on the determinants of a company's decision to opt for secrecy or a registered IP right, mostly in the form of patents. A large part of this literature has mostly been conducted using data from various CIS, which have the advantage that they identify firms that have a product or process innovation and also collect information on the use of alternative appropriability methods. The drawback of using the CIS data, however, is that data are available only at the firm level. The question and the way the theoretical literature models the choice problem, however, concerns the invention. Since companies commonly pursue a variety of activities, the CIS data may be inherently limited in answering the research question. Another issue concerns the patentability of a firm's inventions. The theoretical literature assumes that both patents and secrecy are available to a firm. If, however, an invention is not patentable (e.g., software with the European Patent Office), the choice problem collapses. This creates the risk of confounding the share of patented inventions within the set of patentable inventions (a subset of all inventions) with the share of patented inventions among all inventions. If not all inventions are patentable, this procedure underestimates a firm's decision to patent and biases the inference if there are systematic differences across firms in the share of patentable inventions that they create. As discussed below, this problem, however, can be attenuated at least partly by conditioning the set of companies on the type of innovation that they report (e.g., product innovation that is "new to the market").

There is also a fundamental endogeneity problem in the analysis of these survey data. In his discussion of the original Levin et al. (1987) Yale I study, Gilbert (1987: 823) notes with regard to a set of questions on competition and risk of imitation that "there is an empirical problem with surveys of the relationship between competition and R\&D. If $R \& D$ really does have an effect on entry and competition, then the sample is necessarily biased." Hall et al. (2013) offer another example of the endogeneity problem. They find that patenting firms rate the effectiveness of patents as a mechanism to appropriate returns significantly higher than firms that do not patent. Do firms patent more because they consider patents to be effective means to capitalize on an invention? Or do they rate patents as effective because they have patented (avoiding cognitive dissonance)? Regardless of these problems, some empirical regularities emerge across the various studies that use CIS data on different countries (and therefore slightly different institutional settings). The studies identify some characteristics of the industry and the innovative firms that affect the choice between secrecy and patents.

The more insightful studies in this area, however, rely on invention-level data in combination with largely exogenous variation in the availability of IP protection across jurisdictions. The third type of analysis does 
not use invention-level data, but relies only on exogenous variation in the availability of IP protection across jurisdictions to infer the effect of changes in the strengthening of secrecy protection on research inputs and outputs. This approach avoids the aggregation problem of the survey-based studies, but relies instead on strong assumptions regarding confounding factors that may influence the observed effect of a legal change on the outcome variable. We also briefly discuss a fourth approach that overcomes the difficulty in observing a firm's use of secrecy by using data on court cases. The case-level data reveals information on the companies using (and misappropriating) trade secrets and, often, additional information on the characteristics and value of the inventions protected by secrecy. The problem with this type of analysis, however, is the endogenous selection into litigation. We discuss these four approaches in turn.

\subsubsection{Survey (CIS)-Based Analysis}

As reviewed in section 2, there are a large number of studies that use survey data to learn about the determinants of a firm's assessment of the effectiveness of the different mechanisms and their use. This literature does not test directly any of the theoretical models. Instead, it analyzes determinants of the use of different appropriation mechanisms by companies. Despite the endogeneity and measurement problems discussed above, the availability of some, albeit aggregate, information on a firm's innovative activities, including those that are not patented, as well as some selfreported measure on firms' reliance on the different appropriation mechanisms, has proven useful to establish some robust correlations.

\section{Innovation, Company, and Industry Characteristics}

Product versus process innovations. Studies using survey-based data consistently find that the use of patents is more associated with product innovations than with process innovations. The regression models differ slightly across studies, but product innovations are consistently found to be positively correlated with patenting (inter alia Brouwer and Kleinknecht 1999; Arundel, van de Paal, and Soete 1995; Hall et al. 2013). These results can be interpreted in several ways. Most obviously, it is easier to use secrecy for process innovation than for product innovations. Product innovations are more likely to represent patentable subject matter, which means the uncertainty associated with the grant process may be lower. Patents on process innovations may also reveal more information than patents on products, which means firms prefer to patent product innovations and keep process innovations secret. Finally, product innovations may be, on average, more valuable, hence the costs associated with patenting weigh less heavily.

Size. One of the main findings of the Yale and Carnegie Mellon surveys is that appropriability strategies vary across firms of different size. Larger companies regard patents as more important an appropriation strategy than smaller companies. These findings are confirmed in a large number of studies using the CIS (inter alia Brouwer and Kleinknecht 1999; Arundel et al. 1995; Hall et al. 2013). The principle explanation for this finding is, doubtless, that large firms generally find the use of the patent system lower cost per patent than smaller firms for fixed cost reasons. Equally, small- and medium-sized enterprises (SMEs) may suffer from financial constraints (see below) and, therefore, may decide that applying for a patent is financially too onerous. However, firms that specialize in knowledge production and proof of innovative concept are more likely to be SMEs and for these firms, patents can be quite important, since most of their assets are knowledge assets. In addition, some startups may find that having patents improves their 
access to financing (Hsu and Ziedonis 2008, inter alia).

$\boldsymbol{R} \& \boldsymbol{D}$ intensity. Not surprisingly, patenting is associated with the $R \& D$ performance within firms. In general, it is roughly proportional in the cross section of manufacturing firms (Bound et al. 1984), but somewhat less than proportional within firm (Hausman, Hall, and Griliches 1984). Studies that look at the choice between patenting and secrecy for protection of innovation generally find that R\&D-performing innovating firms are more likely to opt for patents than other innovating firms (presumably because they are more likely to have patentable inventions, e.g., Hall et al. 2013). The numbers in table 2 for U.S. firms clearly confirm this fact.

Incremental versus large innovations. AY suggest that firms that produce large innovations should rely more on secrecy than on patents to protect their inventions. While counterintuitive, this prediction is tested in a paper by Pajak (2010) who uses the French version of the CIS 4 to model the choice between patenting and secrecy (binary variables of self-reported use) where the size of innovation (i.e., whether the innovation is new to the market or only to the industry) appears among the independent variables. He finds the rather equivocal result that in one-third of innovative industries (seven out of twenty-one) a larger innovation is positively correlated with a smaller patent-tosecrecy ratio, in line with the predictions of AY, although for the other two-thirds, a larger innovation favors patenting over secrecy. Moreover, for his sample of small firms in intermediate goods sectors, Pajak finds that firms reporting innovations new to the firm are more likely to use patents, whereas the same firms seem to prefer secrecy for inventions new to the market. This empirical finding should be interpreted with caution, however, as the estimates are merely correlations, the sample size is small (seventy-two firms) and the share of innovating small firms is less than 10 percent (that is, only seven firms).

Financial constraints. Applying for a patent and managing a patent portfolio is expensive. A firm not only has to meet the direct monetary expenses associated with the application process, but it also has to monitor the market for potential infringement and take legal action if the patent is to serve its intended purpose of exclusion. Not surprisingly, firms that report that they are financially constrained tend to use unregistered IP methods. As discussed earlier, the most important reason cited by startups for not patenting is cost (Graham et al. 2009). See also Cordes, Hertzfeld, and Vonortas (1999), who report on a survey of small high technology firms done for the U.S. Small Business Administration, which found that cost of applying and enforcement was the leading reason these firms did not generally use patents. However, Hall et al. (2013) found only very weak evidence that the presence of financial constraints reduced the probability of patenting, once firms' size and sector were controlled for.

Knowledge management practice. Jensen and Webster (2009) use survey data on a set of 785 Australian firms to understand the interaction between firms' knowledge management practices and their choice of knowledge appropriation mechanisms. They find firms that pursue a "closed learning style" rely more on patents and secrecy. Whereas firms that base their technological learning on a more open model that involves exchange across firms are more likely to rely on lead time, brand names, and control over the distribution process. This provides additional evidence that patents and secrecy can act as complementary forms of knowledge appropriation mechanisms within a "closed" knowledge management model that relies on the acquisition of knowledge through licenses, the reading of (patent) publications, and in-house $R \& D$. 
In contrast, Cosh and Zhang (2011) find that UK firms engaged in open innovation practices are more likely to use IP protection methods of all types. Hagedoorn and Ridder (2012) interview and survey European firms involved in open innovation, and report that they tend to use formal contracts to govern their interactions with partners, and that over 90 percent viewed patents and trade secrets as the most important mechanisms for protection of their IP in these relationships, in strong contrast to the Jensen and Webster result.

\section{Impact on Performance}

A small literature based on survey data analyzes the impact that the choice of IP instrument has on the firms' performance. This literature is not very developed, and while issues associated to the identification strategy are unresolved, it is still interesting to report on some results that can offer guidance for future empirical analysis. Hanel (2008) analyzes the use of IP protection for the Canadian manufacturing industry, paying attention to a possible effect on profits. As a first step, he focuses on the propensity of innovative firms to protect their IP. Small firms use IP protection tools less often, whereas "world-first" inventors use every kind of IP protection more frequently than other firms. In the second stage, he focuses on the impact that the use of IP protection has on the firms' profits. He finds that firms that protect their IP increased or maintained their profit.

Hussinger (2006) uses 626 manufacturing firms from the Mannheim Innovation Panel (1998-2000, CIS III) to analyze the impact on the percentage of sales of new products of the use of patents and secrecy. There is a strong positive correlation between patents and sales with new products, whereas there is no relationship between secrecy and innovative sales. This finding is consistent with the hypothesis that patents are preferred to secrecy for protecting valuable inventions in the market phase, but is not supportive of the several models that suggest that smaller, rather than large inventions will be patented. This paper is noteworthy for the fact that the author uses lagged patent holdings as an instrument for the firm's current evaluation of patent importance, controlling, to some extent, for the endogeneity of the choice of IP. Unfortunately, she is unable to look at process innovation due to the lack of data on the degree or importance of this kind of innovation (as opposed to simply its presence).

\subsubsection{Invention-Level Evidence}

The main limitations of the survey-based literature is, on the one hand, the endogeneity of firms' self-reported effectiveness of the various IP mechanisms and their use and, on the other hand, the fact that data are available only at the aggregate, firm-level. There are a few studies that overcome these limitations by using invention-level data in combination with exogenous differences in the legal protection of formal and informal IP over time and across jurisdictions.

Moser (2005) exploits such exogenous differences in the availability of patent protection across countries in the nineteenth century. Moser looks at innovations presented at two World Fairs (London in 1851 and Philadelphia in 1876). Some of these innovations were patented and some were not, which was partly a result of the fact that not all countries had patent laws at that time (Switzerland and Denmark in 1851 and Switzerland and the Netherlands in 1876). Her findings suggest that patent protection is not critical to innovation, but it does have a strong effect on the industrial distribution of innovative activity. Countries without patent protection tended to concentrate in industries where secrecy was effective (as reverse engineering was not so easy and law 
protected trade secrets). Textiles, food processing, scientific instruments and watch making were examples; and countries such as Switzerland, which had no patent system, concentrated in these industries. In contrast, innovations from the United States (which had a relatively low cost and effective patent protection and a patchy way of protecting trade secrets) concentrated in machinery. The Netherlands abolished its patent laws in 1869 and this led, according to Moser, to a substantial increase in innovations coming from food processing, where secrecy was important. In other words, lack of an IP system (or a weak one) does not stop firms from innovating, but can have implications for the direction of innovative activity.

In a similar analysis, Moser (2012) compares British and U.S. inventions exhibited at four global fairs in the nineteenth and twentieth centuries. She has data on over 8,000 inventions exhibited at the Crystal Palace World's Fair in London in 1851, the Centennial Exhibition in Philadelphia in 1876, the World's Columbian Exposition in Chicago in 1893, and the Panama-Pacific International Exposition in San Francisco in 1915. Although both the United States and Britain had a patent system in place throughout the period studied, patenting in Britain was more expensive (by a factor of sixty) than in the United States. Enforcement also appears to have been more difficult and uncertain in Britain than the United States. Despite these substantial differences in the patent systems, Moser finds only a moderate difference in patent rates: 11 percent of the exhibited British and 15 percent of the U.S. inventions were patented. Moser shows that the share of British inventions that were awarded a prize at the Crystal Palace World's Fair is larger among patented inventions. This suggests that more valuable inventions are more frequently patented, directly contradicting the theoretical prediction by AY. The data obtained from exhibition catalogues also reveal large cross-sectional differences across industries: among U.S. inventions, the share of patented inventions in manufacturing of machinery is 44 percent whereas none exist in chemicals. During the time of the Crystal Palace World's Fair, inventions in chemicals could be protected effectively by secrecy, whereas inventions in machinery would have been easy to copy and, therefore, relied more heavily on patents. Perhaps more interestingly, Moser shows that a decrease in the effectiveness of secrecy in the chemical industry (brought about by important inventions in the midnineteenth century-the model of benzene ring and the periodic table) resulted in a substantial increase in patenting. ${ }^{34}$ This intraindustry result supports the explanation that interindustry differences in the reliance on patents are largely driven by their effectiveness in a given sector.

Moser's work is noteworthy not only because of the marked differences in the type of inventions exhibited by inventors from jurisdictions with and without patent protection, but also because she observes the combination of product-level data and patents. Most empirical analysis only has firm-level data, where usually no direct link between products and the different protection mechanisms exists. This is a major shortcoming. Think only of larger companies, which routinely come up with a diverse range of inventions. They are very likely to use all types of protection mechanisms, although the type of protection mechanism used may vary systematically by type of invention. Moreover, products often embody a range of inventions, which may be protected by different mechanisms. Hence, even the combination of product and patent data may not be enough if products embody inventions protected by other means than patents,

\footnotetext{
${ }^{34}$ On patenting and the nineteenth-century German chemical industry, see also Murmann (2003).
} 
which remain unobserved to the researcher. This makes the setup that Moser uses for her study so valuable because the choice of protection mechanisms is limited for largely exogenous reasons.

Having said that, Moser (2013) emphasizes that the evidence obtained from historical data has to be interpreted with care if the objective is to translate the findings to apply to today's world. The patenting landscape has undoubtedly become more complex in recent years, as the range of technologies has expanded, especially in areas where the format of patent rights appears to fit rather poorly. An example is the large increase in the number of patent filings in electrical engineering, especially telecommunication and computer technologies, and the difficulty of delineating patents from each other, which has contributed to the emergence of patent thickets in these technologies (von Graevenitz, Wagner, and Harhoff 2011).

\subsubsection{Evidence from Legal Changes}

The literature offers a third approach to the problem of estimating empirically the impact of the effectiveness of the different appropriation mechanisms on companies' choices and performance. Png (2011) provides an example of analysis of the impact of secrecy on R\&D and the choice between patenting and secrecy without having survey information on a firm's innovative activities or self-reported use of formal and informal IP. He uses the NBER Compustat Patent dataset, which contains firm-level data for all publicly traded companies in the U.S. manufacturing sector, to assess the impact of a strengthening of legal protection of trade secrets through enactment of the Uniform Trade Secrets Act (UTSA). Png finds that enactment of the UTSA is associated with an average drop of 2.4 percent in $R \& D$ among manufacturing firms. However, the figure disguises important heterogeneity across sectors. Whereas the drop is even more pronounced for the medicinal chemicals and botanicals sector ( -4.2 percent), as well as the computer terminals industry $(-4.7$ percent), Png does not find an impact in relatively more R\&D-intensive industries such as pharmaceuticals and computer communications equipment. The results are interpreted as suggesting that own R\&D and knowledge spillovers are complements, i.e., an increase in the use of secrecy leads to a decrease of spillovers, which leads to a net decrease in $\mathrm{R} \& \mathrm{D}$ given the complementarity of spillovers with a firm's own R\&D efforts. Png also analyzes the effect of the strengthening of legal trade secret protection on firms' patent filings, but finds, overall, no discernible impact. However, he finds some evidence that it reduced patenting in sectors in which patents are effective in protecting process innovations. Png interprets these findings as evidence for firms filing patents mostly for strategic reasons, rather than to appropriate returns to an innovation.

Younge and Marx (2012) pursue a similar approach analyzing the effect of a strengthening of secrecy, in the form of employee noncompete agreements in the state of Michigan, on firms' market valuation. Younge and Marx find a strong, promptpositive response on firms' Tobin's $q$ to a law that made noncompete agreements enforceable. The positive response to a strengthening of trade secrecy suggests that companies gain from an improved ability to maintain knowledge within the firm. However, the effect patterns out over time. This effect is stronger in sectors that are known to rely relatively more on secrecy. Younge and Marx interpret evidence from changes in patenting activities of companies to suggest that the eventual drop in firms' market valuation is due to firms' R\&D becoming narrower as a consequence of the law change.

In another study that looks at market valuation and the strength of legal protection of trade secrecy, Carr and Gorman (2001) look 
at the effect of the Economic Espionage Act (EEA), which was enacted in the United States in 1996. It criminalized the theft of trade secrets in the United States (and by U.S. citizens worldwide), which offered an additional legal tool for the enforcement of trade secrecy over existing federal and state law. Carr and Gorman look at changes in the stock market valuation of companies involved in eleven cases filed under EEA between 1996 and 2000. Carr and Gorman gauge the value of the stolen trade secrets from court records and interviews with attorneys and companies. The conservative estimates of these values range widely, between $\$ 0.04$ and $\$ 20$ million, with an average of $\$ 5$ million. Carr and Gorman find a negative response by stock markets to the revelation of trade secrecy theft in seven out of the eleven cases. The magnitude of the stock market loss dwarfs the alleged value of the stolen trade secrets.

The three studies in conjunction provide interesting evidence on the effect of trade secrecy on performance and R\&D. In light of the empirical difficulty of observing the use of secrecy as an appropriation mechanism, relying on exogenous changes in the legal framework that governs secrecy offers a window to studying the effect of secrecy. The results suggest that secrecy is an important protection mechanism of valuable inventions for companies. However, strengthening legal secrecy protection may come at a cost, as it may be correlated with fewer spillovers and even change the type of research that firms conduct.

\subsubsection{Evidence from Litigation}

There is a fourth approach to overcoming the "unobservability" of companies' use of secrecy. Lerner (2006) offers an overview of the entire history of civil state and federal courts cases in California and Massachusetts. However, state cases are limited to cases that were appealed..$^{55}$ This illustrates a fundamental problem in the analysis of court data. The cases that end up in court, and especially those that end with a judgment on the merits in the first instance and are then appealed, are unlikely to be representative of the population of court cases, let alone of all disputes. This means that it is difficult to draw broader lessons on the use of secrecy by companies from these court data. The breakdown of cases by industry in Lerner's study reveals a lot of dispersion of cases across industries. However, most cases are in industries where patents are either not available, or firms traditionally rely on secrecy and copyright, e.g., business services and computer programming, respectively. The data also show that secrecy may be difficult to enforce in court. In slightly less than 40 percent of cases that ended with judgment, misappropriation of trade secrets was found. Damage awards average $\$ 1.5$ million, which Lerner (2006) notes is a lot lower than the damages typically awarded in patent cases. This agrees with the view that, on average, patents protect more valuable inventions than secrecy.

Almeling et al. $(2010,2011)$ collect data on trade secrecy cases in federal, as well as state courts across the United States. Almeling et al. face the same challenges in their data collection as Lerner (2006), which means they only have data on trade secrecy cases in state appellate courts. All in all, they collect 394 trade secrecy cases in federal district courts and 358 trade secrecy cases in state appellate courts for the period 1950-2008 and 1995-2009, respectively. The data show that there was strong growth in trade secrecy cases over the past two decades. In 85 (93) percent of federal (state) court cases, the alleged misappropriator was known to the

\footnotetext{
35 Another problem with the analysis of litigation of trade secrecy cases is that they are difficult to identify in court records because they usually figure under much broader categories, such as contract law.
} 
owner of the trade secret, as he/she was either a (former) employee or business partner. Most trade secrecy cases involve secrets on technical information and know-how, customer lists, and internal business information. There are hardly any cases on negative secrets (i.e., what does not work). Similar to Lerner (2006), Almeling et al. find a win rate of 45 and 41 percent for federal and state cases, respectively. It appears that enforcing trade secrecy vis-à-vis an employee is easier, most likely because discovery (which can be regarded as an important barrier to the enforcement of secrecy) is easier.

Court data offer an interesting opportunity to empirically measure the use of trade secrecy by firms. This allows one to study the characteristics of (a nonrandom set of) companies that rely on secrecy and the information that was protected by secrecy. The limited data on damages offers additional evidence on the value of trade secrets. However interesting these data are, it remains unclear what they tell us about the use of trade secrets, their characteristics and value in the population of firms.

\subsection{Combined Patent-Secrecy Strategy}

There is hardly any broad empirical evidence on whether firms in fact pursue the combined patent-secrecy strategy for a single invention, what its determinants are, and what its consequences on performance and innovation are. This is explained by the fact that the empirical analysis of the use of patents in combination with secrecy is challenging. With firm-level data, it is impossible to determine exactly what is protected by which protection instrument. The combined use of patents and secrecy has to be identified at the invention or product level. Not only are different elements of an invention often protected by patents or secrecy, patents and secrecy may also be used to protect the same element at different stages of the innovative process. Anton, Greene, and Yao
(2006: 9) state, "[b]ecause innovations are rarely composed of a monolithic piece of knowledge, a combination of patenting and secrecy is common."

Theoretical models tend to focus on the invention-level and tackle the question of which protection tool is most suitable for this particular invention. It has proven difficult to translate these theory models into empirical research because the available firm-level data cannot distinguish whether patents and secrecy are used for one or more particular inventions. Indeed, data surveys that are commonly used for this type of analysis (like the CIS) are unable to tell whether firms use secrecy and patents for the same inventions and whether they apply to the different stages of the innovation process, where patents versus secrecy might be differentially important.

Graham and Hegde (2012) offer some evidence by looking at the possibility to maintain patents unpublished until grant. The America Inventor's Protection Act (AIPA) of 1999 was designed to eliminate this possibility. It required publication of any patent application after eighteen months, but offered an opt out. If no patent protection is sought in other jurisdictions, the applicant could still choose to maintain the application unpublished until grant. Graham and Hegde look at all patent grants filed with the USPTO between 1996 and 2005 to find that post-AIPA (2001-05), 7.5 percent of filings opt out. The largest share of assignees opting out is found in information and communication technologies (ICT). The authors find no evidence for small applicants more frequently opting out than large applicants. For small applicants, there is also a positive correlation between patent value and not choosing to opt out. This would suggest that the combination of patenting and secrecy in the form of delayed publication is not chosen for more valuable inventions. The evidence by Graham and Hegde (2012) looks 
at a very specific type of combining patenting with secrecy. The study is also subject to considerable selection bias, because foregoing patenting in other jurisdictions is very costly in the case of any valuable invention. No doubt, this explains the fact that opting out is most frequent in ICT technologies, which are used by a sector that engages in patent portfolio racing (a type of strategic patenting) where most individual patents are not that important, but quantity matters. Nevertheless, it illustrates one way in which these two appropriation mechanisms, which are in principle substitutes, can be employed in combination for the same invention.

\subsection{No Patent, No Secrecy-Disclosure}

Despite a well-developed body of theoretical work on the use of disclosure by companies, there is a lack of empirical analysis. Merges (2004) discusses the role that disclosure plays in two specific examples: the Merck Gene Index and IBM's investment in Linux. In 1995, the pharmaceutical company Merck created a public database in which it discloses gene sequences and makes them publicly available. Merck's motivation was to prevent patenting in this area, which would affect Merck's business because it widely uses gene sequences as an input. The logic is similar in the case of IBM's investment in Linux. The open source operating system offers a public domain alternative to Microsoft's Windows platform. Since Microsoft's dominance in the operating system market raises input costs for IBM, its investment in Linux offers an opportunity to build an IP-free system, which would lower the costs of an essential input for IBM. These examples illustrate the strategic use of disclosure by companies.

Somewhat broader empirical evidence is provided by Henkel and Pangerl (2008), who report on the qualitative evidence collected from fifty-six interviews (in 2005 and 2006) with thirty-seven large publicly traded manufacturing companies and patent practitioners in Germany. The interviews reveal that defensive publishing is indeed widely used. One of the main motivations for publishing instead of patenting is the lower cost of publishing. Obviously, this argument weighs more heavily for lower value inventions, or for those inventions that are complementary to patented inventions and can therefore be protected, to some extent, by them. Still, patent publications are often used as a vehicle for defensive publications and the cost savings arise from not having to prosecute the patent to grant. Defensive publications are mainly seen as a way to maintain freedom to operate. To ensure freedom to operate, companies choose to disclose, instead of maintaining the invention secret. Nevertheless, the interviewees indicate that there are ways of legally disclosing while maintaining de facto secrecy, for example by choosing obscure places (or foreign languages) for publication, instead of standard outlets such as IP.COM. Such a strategy, of course, contradicts the theoretical models in which defensive publications signal costs or raise the prior art bar. According to Henkel and Pangerl (2008), there is no evidence for disclosure to be used strategically in patent/R\&D races. Companies claimed that they are usually not sufficiently aware of their position in a race to use disclosure strategically. Even if companies knew their position in such a race, companies still indicated that they would not rely on strategic disclosure for fear over encouraging entry of new competitors, contradicting the assumptions of some of the theoretical models.

\subsection{The Choice of Other Forms of IP}

Unlike informal methods of IP protection such as secrecy and lead time, the alternative formal methods of IP protection such as trademarks and copyright are 
not necessarily substitutes for patents, but instead offer the ability to protect different aspects of an innovation. Although the theoretical literature focuses on the choice between secrecy and formal IP in the form of patents, in reality, the use of other forms of formal IP, especially trademarks and copyright, is far more widespread. This section briefly reviews the relatively sparse empirical evidence on the use of these methods of protection.

\subsubsection{Trademarks}

Trademarks are probably the most widely used method of registered IP protection, as they are available to essentially any firm selling a good or service. In some cases, they can represent an extremely valuable and long-lived brand, but most end up being of little value or having a relatively short life. Empirical studies into the effect of trademarking on firm performance have been scarce, although this is changing with the advent of computerized data availability at Trademark Offices, notably the Office for Harmonisation in the Internal Market of the European Union. ${ }^{\sqrt{6}}$ Most of the available studies look at the association of trademark ownership with firm value and typically find that the average trademark is valued positively but by less than the average patent, and also that trademarks are more important to service sector firms.

Seethamraju (2003) analyzed the value of trademarks in 237 U.S. firms over 1993-97, finding a positive role for trademarking on sales and also on market value. Griffiths, Jensen, and Webster (2011) used a sample of slightly less than 2,700 large Australian firms over 1989-2002 and found that the stock of trademarks was a significant determinant of profits, but with a smaller impact than

\footnotetext{
36 Very recently, the USPTO has released a comprehensive U.S. trademark database (Graham et al. 2013), but it is too early to see research using these data.
}

either patents or registered designs. They also found that the value of a trademark was rising over their data period. Their work is consistent with the earlier work of Bosworth and Rogers (2001), who had used a sample of sixty Australian firms from 1994-96 and found a positive but insignificant coefficient for trademarks in the market value equation that also included R\&D and patents. They also noted that trademarks were somewhat more important to nonmanufacturing firms than manufacturing firms.

Greenhalgh and Rogers (2007b) analyze a large sample of publicly quoted UK firms from 1996-2000, with both manufacturing and services firms being included. They look at whether any trademark activity, and also the effects of increasing trademark intensity, impact on performance, as measured by Tobin's $q$, or the ratio of market value to the book value of the tangible assets. The results indicate that a firm's stock market value is positively associated with trademark activity (as well as with R\&D and patents). They find larger differences between firms with and without trademarks in the service sector than for manufacturing. They also find bigger differences in Tobin's $q$ when the services firm is applying for European Community trademarks, rather than just applying for UK marks. When looking at intensities (i.e., the ratio of trademarks to assets), they find an increase in the intensity of Community trademarks raises market value for both manufacturing and services, but this relationship weakened over their data period. Since there was an increase in trademarks during the late 1990s, a fall in the estimated value of such activity might be expected. Greenhalgh and Rogers's interpretation of their findings is that, in general, trade mark activity proxies for a range of other, unobservable, firm-level characteristics, including innovation that increase both productivity and product prices. 
Greenhalgh and Rogers (2007b) also analyze whether greater trademark intensity raises productivity growth. They find that higher trademark intensity has some positive association with productivity growth in services, but the results are relatively weak for manufacturing firms. These results for the relationship between productivity and trademarks were broadly consistent with those derived for their quoted firm sample using the market value approach, suggesting that stock markets are efficient in estimating the likely benefits of new intangible assets, and that managers are not just seeking trademarks to follow a "management fad." Even so, the marginal returns to extra trademarks per firm were diminishing quite rapidly over the period, as indicated by exploration of the interaction of time trends with trademark intensity, suggesting decreasing returns to further proliferation of product variety.

Empirical evidence on the determinants of trademarking is similarly sparse. Jensen and Webster (2004) consider the increase in trademarking in Australia from 1976 to 2002. They find that the increases are associated with a) increasing globalization, b) the growth of household income, c) an increase in service sector activity, and d) the fact that trademarking appears to be linked to increases in product innovation and design. Rogers and Greenhalgh (2006) consider UK financial service sector firms (1996-2000), finding that while larger firms account for more trademarks, the trademark to employment ratio is higher for small firms. They also investigate whether stock market listed firms and more diversified firms trademark more, but find no role for either factor.

\subsubsection{Copyright}

Empirical analysis of the value of copyright is difficult since there is (currently) no legal requirement to register creative work. ${ }^{37}$ Nevertheless, there are a few studies that generate some information on the economic role of copyright. Country-level studies provide some background. A study on the United States during the period when copyright had to be registered (and renewed) concluded that around 80 percent of copyright had little economic value (see Landes and Posner 2003, who looked at the 1910-1991 period). This result is consistent with the generally very skew distribution of value for a wide range of innovation measures (Scherer 1998).

Baker and Cunningham (2009) look at aggregate quarterly copyright registration in the United States and Canada during the 1986-2005 period and how it responded to changes in the copyright term extensions and other changes to the law, finding a small positive impact of term extension. However, there are some problems with the empirical setup, due to the lack of a requirement for registration unless legal enforcement is contemplated, and also due to the timing of such registration. Png and Wang (2009) look at the impact of copyright extensions on the production of movies in twenty-three OECD countries, and found no statistically robust evidence that copyright term extension was associated with higher movie production. This result is not surprising, since the net present value of such a twenty-year increase is very low (if a standard discount rate is used). They also looked at the impact of European revisions to copyright law in response to the EU's Rental Directive (which arguably strengthened the rights of movie producers to receive returns from rentals) and found no effect. Li, MacGarvie, and Moser (2014) use data at the book-level for the period 1790-1840 to estimate the effect of copyright

\footnotetext{
${ }^{37}$ Historically some countries, including the United States, required copyright to be registered prior to enforcement, but under TRIPs, countries cannot make such a requirement.
} 
extension through the British Copyright Act of 1814 on book prices. The authors show that the copyright act effectively prolonged copyright protection only for dead authors, which allows them to compare changes due to the term extension for books by dead and living authors. The results indicate a large positive effect on book prices, that is, the price of a book by a dead author significantly increased in response to the term extension.

Waldfogel (2012) argues that it is important to look at the quality of music created, as well as the quantity sold, as an indicator of the impact on consumer surplus from the rise of low and free methods of distribution over the Internet. He uses three indicators of quality: critics' ratings, and the relative taste for recordings of various vintages (before and after the rise of Napster) as measured both by sales and airplay. All three indicate that quality has slightly increased, rather than declining, with the advent of the Internet and the changes in distribution it has induced, suggesting that increases in free or lower-cost access have so far not had a negative impact on the incentives for the creation of musical recordings.

Firm-level studies on copyright are more difficult. One approach is to use data on court actions. Baker and Cunningham (2006) look at the effect of U.S. federal court decisions that broadened copyright on the market value of firms. They find that a new copyright statute can raise return on equity by between 0.4 percent and 2.1 percent, while a high court decision can raise returns by 0.1 percent to 1.1 percent. In a similar type of study, Mazeh and Rogers (2006) find that plaintiffs in copyright disputes have higher market values than a peer group of similar firms. Overall, however, the empirical evidence on the value of copyright, especially at the firmlevel, is sparse.

It is probably worth emphasizing that, for copyright as for other formal IP protection methods, there is a great difference between its role as an ex ante incentive and as an ex post profit generator. It is probably safe to say that there is very little evidence that the incentive to produce creative works is impacted by term extensions of the kind we have seen recently, but that does not mean that the firms holding the very small share of copyrighted works that have a long lifetime (think of Disney Films) will not experience market value effects in response to extensions of the term.

\subsubsection{Multiple and Overlapping IP Use}

As pointed out above, firms typically have more than one invention and, furthermore, tend to bundle different IP protection tools (e.g., Levin et al. 1987). In fact, most of the surveys that ask firms about their preferences for various IP protection methods find that their answers are correlated, implying that firms have a general taste for IP that manifests itself as a preference for all the different methods. ${ }^{38}$

Even when restricting attention to registered IP rights, the empirical analysis of IP bundles remains challenging because with firm-level data, it is impossible to determine exactly what is protected by which IP protection instrument. The existing literature on the use of IP bundles has focused on the question of whether different forms of IP act as complements or substitutes (i.e., whether the return to using one type of IP increases or decreases in the use of another form of IP). Graham and Somaya (2006) suggest that IP protection methods

\footnotetext{
${ }^{38}$ In unpublished work, Hall (2013) shows this for UK firms. After controlling for firm size, age, export status, ownership, $\mathrm{R} \& \mathrm{D}$, and two-digit industry, the correlations among the propensity to use four different kinds of formal IP (patents, trademarks, copyright, and design rights) range from 0.55 to 0.7 , slightly higher than the unconditional correlations of 0.45 to 0.6 . This suggests that, either firms have heterogeneous tastes for IP in general, or there is considerable heterogeneity in the importance of innovation to different firms, even controlling for basic characteristics like size and industry.
} 
are often complements, rather than substitutes, and offer as an example computer software, where copyright, trademarks, and patents are often used together. The difficulty in examining the use of these methods empirically is that copyright is often unregistered and trademark data can be rather noisy. The authors address this problem by looking at changes in litigation rates for copyright and trademarks within firms over time. They show that after they control for firm size, age, $R \& D$, income, managerial attention to IP, firm IP resources, and firm fixed effects, the residuals in the copyright and trademark litigation rates are correlated, suggesting complementary use of the two above and beyond the overall IP profile of the firm. Llerena and Millot (2013) analyze possible complementarities between patents and trademarks. They forward the theoretical idea that trademarks can complement patents by providing exclusivity for a product's goodwill that was built while a patent is in force. In contrast, patents and trademarks act as substitutes as long as a patent is in force because competition is precluded even without trademark protection. The empirical evidence provides rather weak evidence for such complementarities, although there are interesting differences across industries with patents and trademarks acting as complements in pharmaceuticals and substitutes in the computer and electrical equipment industry. Nevertheless, these results have to be interpreted with caution because only data at the firm-level is available to test these relationships empirically.

\section{Patents versus Secrecy: Welfare}

The empirical fact that many firms choose to use secrecy, rather than patents, has prompted various theoretical models that analyze the impact of this choice on social welfare. In our context, one of the issues at stake concerns the role of disclosure, where here this is defined as the full description of the invention contained in the patent document. One of the basic rationales of the patent system is to encourage disclosure, since this prevents the duplication of research and, once the patent has expired, allows "those skilled in the art" to quickly replicate the invention. This rationale is referred to as the contract theory of patents by legal scholars, as opposed to the reward theory (which focuses on incentives to invent). The role of disclosure in contract theory is very specific: prevent duplication and allow rapid diffusion once the patent has expired (for more detailed discussion see Anderson 2011).

In several of the surveys mentioned previously, firms or inventors were asked for a qualitative assessment as to how important patents were as a source of information for a particular invention. Cockburn and Henderson's (2003) survey data shows that only a third of respondents-who are mostly IP counsels-conduct a prior art search before starting new R\&D or product development. This may have multiple reasons. For example, Lemley (2008) is one of many with experience as practitioners to suggest that IT and biotech firms in the United States purposefully ignore existing patent documents in order to avoid charges of willful infringement, and that researchers in these fields execute their research without conducting prior art searches. Holbrook (2006) suggests also that the eighteen-month lag between application and publication (and possibilities to delay publication) renders the information disclosed by patents largely obsolete in a range of fast moving industries. ${ }^{39}$ Furthermore, restrictions on the legitimate use of patented inventions for

\footnotetext{
39 Holbrook (2006) notes that, in the United States, in contrast to granted patents, to infringe on a patent after it was published but before it was granted, the infringer had to be aware of the publication. This creates incentives not to review patent publications before they are granted.
} 
experimentation could limit the use of patent disclosure. However, Ouellette (2012) provides contrasting evidence that suggests that managers of nanotechnology firms find it useful to read patent documents. There is also regional variation: Cohen et al. (2002) find that Japanese inventors are twice as likely as U.S. inventors to obtain information about future research directions from patents. U.S. companies, in contrast, generally prefer other sources of information over patents. Walsh and Nagaoka (2009) confirm these large differences in the importance of patents between U.S. and Japanese inventors, with Japanese inventors about twice as likely to use patents to acquire information. In line with these studies, Gambardella, Harhoff, and Nagaoka (2011) find for their large inventor survey (around 20,000 inventors in Europe, the United States, and Japan) that patents are particularly important sources of information in a small number of technical areas-such as polymers, organic chemicals, pharmaceuticals, petrochemical and materials chemistry-and that Japanese inventors assign greater importance to information in patents than either European or U.S. inventors. Apart from asking inventors about the importance of patents as a source of information, Gambardella, Harhoff, and Nagaoka (2011) also ask inventors to quantify the time saved in an invention process when compared to a situation in which the information from patents had not been available. This offers a way of quantifying potential cost savings incurred by inventors due to knowledge of the patent literature. Time savings from disclosures follow a highly skew distribution, with estimated median values of 5.9 hours and mean values of 11.5 hours. There is considerable heterogeneity across technical fields-median values range between one hour (digital communication technology) and thirty-six hours (organic chemicals). Thus, in fields where patents have strong impact on appropriation, such as chemicals and pharmaceuticals, disclosure effects also appear to matter the most. Still, even in those sectors costs savings from patent disclosure implied by these figures are, at best, modest. It is possible, however, that disclosure through patents has other effects that are not captured by the survey question, such as whether reading patent publications avoids duplication of research, either by not even commencing a new research project or by leading the inventors to abort an ongoing project early. But it is hard to gauge how important these considerations are, empirically. Moreover, measuring the effect of disclosure only based on how important the patent literature is for innovation may be too narrow. If there is additional (informal) disclosure, which is enabled by a patent (if the invention had to be kept secret, it could not be informally discussed), the disclosure effects could be substantially larger. Quantifying any such informal disclosure effects is challenging, however.

There are relatively few theoretical papers that examine the welfare implications of patent system design in the presence of the patent-secrecy choice. Earlier, we discussed the pioneering work of Scotchmer and Green (1990), who focus on the welfare consequences for subsequent invention induced by the choice of first-to-file priority versus first-to-invent, showing that neither system can achieve first best disclosure and invention levels. Denicolò and Franzoni (2004) study the welfare consequences of prior-user rights. Using a model of an inventor and a follower who may try to imitate, they show that when there are prior-user rights (the right of the first inventor to use an invention which it had kept secret even if it is later patented by a third party), second inventors will not patent in equilibrium. When a patent system is optimized (that is, when patent life is optimal for welfare), introducing prior-user rights cannot improve welfare. In the more realistic situation where patent life is seldom optimal, the incentive to innovate 
is increased by the introduction of prioruser rights, but there is more duplication of research, and the welfare effects are unclear. They conclude that prior-user rights may be optimal in highly competitive settings with underinvestment in $\mathrm{R} \& \mathrm{D}$, and also that trade secrecy is seldom preferable to patenting, from a welfare perspective.

Cugno and Ottoz (2006) present a model in which inventions that are kept secret can be licensed. They assume that innovators have already obtained the innovation and only face the decision whether to patent or keep it secret. Cugno and Ottoz also assume that patented inventions cannot be imitated without infringement, that is, patents protect an invention perfectly. In this case, the only relevant variable determining profits from patenting is patent lifetime. In the case of secrecy, competitors can legally duplicate the invention at some positive cost. It is this threat of duplication that leads the innovator to license the secret innovation to competitors to keep them from imitating. A simple comparison of welfare under the assumption that licensing does not entail transaction costs reveals that the ex post welfare loss associated with patenting is larger than that for secrecy. This result is based on a number of rather unrealistic assumptions such as that patents perfectly prevent imitation or that the decision to patent or maintain an invention secret does not affect R\&D incentives. So its applicability is doubtful.

\section{Conclusions}

Although not ideal, due to the level of aggregation (firm level, rather than product level) and the qualitative nature of the questions, the survey evidence we reviewed gives a rather consistent overall impression of IP use and its importance for firms. A number of valuable stylized facts about invention, company, and industry characteristics that influence the choice between patenting, secrecy, and other formal, as well as informal, mechanisms emerge from these surveys. Certainly the most robust finding is heterogeneity in the use of patents across industries. Patents play an important role in the pharmaceutical and chemical industry, and sometimes in the medical instrument industry and parts of the machinery sector. We also learn that most firms consider patents a relatively ineffective means to protecting their inventions. Instead, they favor a range of different informal protection mechanisms, above all lead time. But companies also regard secrecy as more effective than patents. Finally, from the survey evidence it is apparent that firms tend to treat various kinds of IP protection as complements, in the sense that use of one makes it highly probably they will use the others.

From our review of the theoretical literature, the heterogeneity of firm behavior with respect to IP protection should come as no surprise: theory suggests that the nature of innovation (product versus process and discrete versus complex) along with the degree of competition among innovators and in the product market are the key factors that shape a firm's propensity to use secrecy, rather than patents. Since these factors also vary across time and across countries, we should also expect to see the propensity to patent varying. Even in patent-intensive industries, secrecy can be important in protecting process innovations. This apparent inconsistency with theory is due to the fact that many firms have a bundle of inventions and innovations, and their different characteristics may call for different protection mechanisms.

Our review also highlights that most of the theoretical work concentrates on the choice of patents versus secrecy. The binary choice between two substitutes is a convenient assumption that helps identify a range of factors that influence the decision to use patents or secrecy. One of the key determinants of the choice is the disclosure required by 
patents and the strategic options (the possibility to influence competitors' behavior) that disclosure through patent publications confers to companies. The available survey data, however, suggest that patents and secrecy are often used as complements. Moreover, the focus on patents is too narrow, as trademarks and copyright are far more widely used formal IP rights than patents. Similarly, secrecy is not the most effective and frequently used informal appropriation method. The narrow focus of the theoretical literature creates a gap between the theoretical models and the empirical work in this area.

An important limitation in most of the existing empirical work, relative to the theory, is the absence of data at the invention level. Theory models the choice between patenting and secrecy at the invention level; most empirical studies rely on firm-level data. Since companies pursue a multitude of activities, this makes it difficult to infer from the firm-level data information on choices made at the invention-level.

From a policy point of view, the lack of a better theoretical understanding of the trade-off that companies face when choosing between the large range formal and informal IP methods represents a challenge. The impact of changes to the patent system or the law governing trade secrecy depends on their effect on the trade-off between the use of different appropriation mechanisms. Our review suggests that a simplistic view of this trade-off, with companies patenting by default patentable inventions, is misplaced. The available empirical evidence strongly suggests that, in most industries, patents are not seen as an effective tool to appropriate returns to innovation-especially not in isolation. Instead, companies appear to use a combination of different appropriation mechanisms even for the same invention. For policy, an improved understanding of possible interactions and overlaps between the different mechanisms would be useful.
Our review shows that there is ample room for further research in this area. However, further research in the form of additional crosssectional survey evidence may not be the best way forward. As discussed above, survey data in this area have some built-in limitations that restrict the insights that can be derived from the analysis of these data. Despite the limitations, the various robust stylized facts generated by the survey data are useful in guiding further theoretical and empirical work. One such stylized fact is the joint use of different forms of IP, including the joint use of patents and secrecy. It might be worthwhile to relax the assumption that patents and secrecy are mutually exclusive and to consider a more complex and realistic scenario in which companies employ different mechanisms to protect the same invention. From an empirical point of view, the small literature that has used the combination of invention-level data with exogenous changes in the legal regimes governing the patent-secrecy trade-off offers the most insightful findings. If patent protection is not available, there is still innovation, albeit innovation that can be more easily protected by informal mechanisms including secrecy. This literature, however, is based on the same type of data and setting: inventions exhibited at fairs between the mid-nineteenth and mid-twentieth centuries. It would be useful to have these findings confirmed by data from different settings.

\section{REFERENCES}

- Allen, Robert C. 1983. "Collective Invention." Journal of Economic Behavior and Organization 4 (1): 1-24. Almeling, David S., Darin W. Snyder, Michael Sapoznikow, Whitney E. McCollum, and Jill Weader. 2010. "A Statistical Analysis of Trade Secret Litigation in Federal Courts." Gonzaga Law Review 45 (2): 291-334.

Almeling, David S., Darin W. Snyder, Michael Sapoznikow, Whitney E. McCollum, and Jill Weader. 2011. "A Statistical Analysis of Trade Secret Litigation in State Courts." Gonzaga Law Review 46 (1): 57-101.

Anderson, J. Jonas. 2011. “Secret Inventions.” Berkeley Technology Law Journal 26 (2): 917-78. 
Anton, James J., Hillary Greene, and Dennis A. Yao. 2006. "Policy Implications of Weak Patent Rights." In Innovation Policy and the Economy, Volume 6, edited by Adam B. Jaffe, Josh Lerner, and Scott Stern, 1-26. Cambridge, Mass. and London: MIT Press.

Anton, James J., and Dennis A. Yao. 1994. "Expropriation and Inventions: Appropriable Rents in the Absence of Property Rights." American Economic Review 84 (1): 190-209.

-Anton, James J., and Dennis A. Yao. 2004. "Little Patents and Big Secrets: Managing Intellectual Property." RAND Journal of Economics 35 (1): 1-22.

-Anton, James J., and Dennis A. Yao. 2008. "Attracting Skeptical Buyers: Negotiating for Intellectual Property Rights." International Economic Review 49 (1): 319-48.

-Arora, Ashish. 1997. "Patents, Licensing and Market Structure in the Chemical Industry." Research Policy 26 (4-5): 391-403.

Arrow, Kenneth. 1962. "Economic Welfare and the Allocation of Resources for Invention." In The Rate and Direction of Inventive Activity: Economic and Social Factors, edited by Richard R. Nelson, 609-25. Princeton: Princeton University Press.

-Arundel, Anthony. 2001. "The Relative Effectiveness of Patents and Secrecy for Appropriation." Research Policy 30 (4): 611-24.

-Arundel, Anthony, and Isabelle Kabla. 1998. "What Percentage of Innovations Are Patented? Empirical Estimates for European Firms." Research Policy 27 (2): 127-41.

Arundel, Anthony, Gert van de Paal, and Luc Soete. 1995. "Innovation Strategies of Europe's Largest Industrial Firms: Results of the PACE Survey." European Innovation Monitoring System Publication 23.

- Baker, Matthew J., and Brendan M. Cunningham. 2006. "Court Decisions and Equity Markets: Estimating the Value of Copyright Protection." Journal of Law and Economics 49 (2): 567-96.

Baker, Matthew J., and Brendan M. Cunningham. 2009. "Law and Innovation in Copyright Industries." Review of Economic Research on Copyright Issues 6 (1): 61-82.

- Baker, Scott, and Claudio Mezzetti. 2005. "Disclosure as a Strategy in the Patent Race." Journal of Law and Economics 48 (1): 173-94.

- Bar, Talia. 2006. "Defensive Publications in an R\&D Race." Journal of Economics and Management Strategy 15 (1): 229-54.

Bessen, James, and Michael J. Meurer. 2008. Patent Failure: How Judges, Bureaucrats, and Lawyers Put Innovators at Risk. Princeton and Oxford: Princeton University Press.

Bhattacharya, Sudipto, and Sergei Guriev. 2006. "Patents vs. Trade Secrets: Knowledge Licensing and Spillover." Journal of the European Economic Association 4 (6): 1112-47.

-Blind, Knut, Jakob Edler, Rainer Frietsch, and Ulrich Schmoch. 2006. "Motives to Patent: Empirical Evidence from Germany." Research Policy 35 (5):
$655-72$.

-Boldrin, Michele, and David K. Levine. 2013. "The Case against Patents." Journal of Economic Perspectives 27 (1): 3-22.

- Bosworth, Derek, and Mark Rogers. 2001. "Market Value, R\&D and Intellectual Property: An Empirical Analysis of Large Australian Firms." Economic Record 77 (239): 323-37.

Bound, John, Clint Cummins, Zvi Griliches, Bronwyn H. Hall, and Adam Jaffe. 1984. "Who Does R\&D and Who Patents?” In RuD Patents, and Productivity, edited by Zvi Griliches, 21-54. Chicago and London: University of Chicago Press.

Brouwer, Erik, and Alfred Kleinknecht. 1999. "Innovative Output, and a Firm's Propensity to Patent: An Exploration of CIS Micro Data." Research Policy 28 (6): 615-24.

Carr, Chris, and Larry Gorman. 2001. "The Revictimization of Companies By the Stock Market Who Report Trade Secret Theft under the Economic Espionage Act." The Business Lawyer 57 (1): 25-53.

Cockburn, Iain M., and Rebecca Henderson. 2003. "Survey Results from the 2003 Intellectual Property Owners Association Survey on Strategic Management of Intellectual Property." http:/www.ipo. org/wp-content/uploads/2013/04/survey_results_ revised.pdf.

Cohen, Wesley M., Akira Goto, Akiya Nagata, Richard R. Nelson, and John P. Walsh. 2002. "R\&D Spillovers, Patents and the Incentives to Innovate in Japan and the United States." Research Policy 31 (8-9): 1349-67.

Cohen, Wesley M., Richard R. Nelson, and John P. Walsh. 2000. "Protecting Their Intellectual Assets: Appropriability Conditions and Why U.S. Manufacturing Firms Patent (or Not)." National Bureau of Economic Research Working Paper 7552.

Comanor, William S., and F. M. Scherer. 1969. "Patent Statistics as a Measure of Technical Change." Journal of Political Economy 77 (3): 392-98.

Cordes, Joseph J., Henry R. Hertzfeld, and Nicholas S. Vonortas. 1999. "A Survey of High Technology Firms." http://archive.sba.gov/advo/research/ rs189tot.pdf.

Cosh, Andy, and Joanne Jin Zhang. 2011. Open Innovation Choices-What Is British Enterprise Doing? London: Imperial College London; Cambridge: Centre for Business Research, University of Cambridge.

Cugno, Franco, and Elisabetta Ottoz. 2006. "Trade Secret vs. Broad Patent: The Role of Licensing." Review of Law and Economics 2 (2): 209-21.

Denicolò, Vincenzo, and Luigi Alberto Franzoni. 2004. "Patents, Secrets, and the First-Inventor Defense." Journal of Economics and Management Strategy 13 (3): 517-38.

-Encaoua, David, Dominique Guellec, and Catalina Martínez. 2006. "Patent Systems for Encouraging Innovation: Lessons from Economic Analysis." Research Policy 35 (9): 1423-40.

Encaoua, David, and Yassine Lefouili. 2005. "Choosing Intellectual Protection: Imitation, Patent Strength 
and Licensing." Annales d'Économie et de Statistique 79-80: 241-71.

-Erkal, Nisvan. 2005. "The Decision to Patent, Cumulative Innovation, and Optimal Policy." International Journal of Industrial Organization 23 (7-8): 535-62. Foray, Dominique, and Liliane Hilaire Perez. 2006. "The Economics of Open Technology: Collective Organization and Individual Claims in the "Fabrique Lyonnaise' during the Old Regime." In New Frontiers in the Economics of Innovation and New Technology: Essays in Honour of Paul A. David, edited by Cristiano Antonelli, Dominique Foray, Bronwyn H. Hall, and W. Edward Steinmueller, 239-54. Cheltenham, U.K. and Northampton, Mass.: Elgar.

-Friedman, David D., William M. Landes, and Richard A. Posner. 1991. "Some Economics of Trade Secret Law.” Journal of Economic Perspectives 5 (1): 61-72.

- Gambardella, Alfonso, and Bronwyn H. Hall. 2006. "Proprietary versus Public Domain Licensing of Software and Research Products." Research Policy 35 (6): 875-92.

Gambardella, Alfonso, Dietmar Harhoff, and S. Nagaoka. 2011. "The Social Value of Patent Disclosure." Unpublished.

Gilbert, Richard. 1987. "Appropriating the Returns from Industrial Research and Development: Comment." Brookings Papers on Economic Activity 3: 821-24.

Gilbert, Richard J., and David M. G. Newbery. 1982. "Preemptive Patenting and the Persistence of Monopoly." American Economic Review 72 (3): 514-26.

-Gill, David. 2008. "Strategic Disclosure of Intermediate Research Results." Journal of Economics and Management Strategy 17 (3): 733-58.

Graham, Stuart J. H. 2004. "Hiding in the Patent's Shadow: Firms' Uses of Secrecy to Capture Value from New Discoveries." https://smartech.gatech. edu/xmlui/handle/1853/10725.

-Graham, Stuart J. H., Galen Hancock, Alan C. Marco, and Amanda Fila Myers. 2013. "The USPTO Trademark Case Files Dataset: Descriptions, Lessons, and Insights." Journal of Economics and Management Strategy 22 (4): 669-705.

Graham, Stuart J. H., and Deepak Hegde. 2012. "Do Inventors Value Secrecy in Patenting? Evidence from the American Inventor's Protection Act of 1999." http://papers.ssrn.com/sol3/papers. cfm?abstract_id=2170555.

Graham, Stuart J. H., Robert P. Merges, Pam Samuelson, and Ted Sichelman. 2009. "High Technology Entrepreneurs and the Patent System: Results of the 2008 Berkeley Patent Survey." Berkeley Technology Law Journal 24 (4): 1255-1327.

Graham, Stuart J. H., and Ted Sichelman. 2008. "Why Do Start-Ups Patent?" Berkeley Technology Law Journal 23 (3): 1063-97.

Graham, Stuart J. H., and Deepak Somaya. 2006. "Vermeers and Rembrandts in the Same Attic: Complementarity between Copyright and Trademark Leveraging Strategies in Software." http://papers. ssrn.com/sol3/papers.cfm?abstract_id=887484.

-Green, Jerry R., and Suzanne Scotchmer. 1995. "On the Division of Profit in Sequential Innovation." RAND Journal of Economics 26 (1): 20-33.

Greenhalgh, Christine, and Mark Rogers. 2007a. "The Value of Intellectual Property Rights to Firms and Society." Oxford Review of Economic Policy 23 (4): 541-67.

Greenhalgh, Christine, and Mark Rogers. 2007b. "Trade Marks and Performance in UK Firms: Evidence of Schumpeterian Competition through Innovation." http://www.economics.ox.ac.uk/Research/wp/pdf/ paper300.pdf.

Griffiths, William, Paul H. Jensen, and Elizabeth Webster. 2011. "What Creates Abnormal Profits?" Scottish Journal of Political Economy 58 (3): 323-46.

Griliches, Zvi. 1990. "Patent Statistics as Economic Indicators: A Survey." Journal of Economic Literature 28 (4): 1661-1707.

Hagedoorn, John, and Ann-Kristin Ridder. 2012. "Open Innovation, Contracts, and Intellectual Property Rights: An Exploratory Empirical Study.” United Nations University Maastricht Economic and Social Research Institute on Innovation and Technology Working Paper 2012-025.

Hall, Bronwyn H. 2013. "Unpublished Work for the UK Department of Business, Innovation, and Skills." Manufacturing Foresight Project.

- Hall, Bronwyn H., Christian Helmers, Mark Rogers, and Vania Sena. 2013. "The Importance (or Not) of Patents to UK Firms." Oxford Economic Papers 65 (3): 603-29.

Hanel, Petr. 2008. "The Use of Intellectual Property Rights and Innovation By Manufacturing Firms in Canada." Economics of Innovation and New Technology 17 (4): 285-309.

Harabi, Najib. 1995. "Appropriability of Technical Innovations an Empirical Analysis.” Research Policy 24 (6): 981-92.

- Hausman, Jerry, Bronwyn H. Hall, and Zvi Griliches. 1984. "Econometric Models for Count Data with an Application to the Patents-R\&D Relationship." Econometrica 52 (4): 909-38.

-Hegde, Deepak, David C. Mowery, and Stuart J. H. Graham. 2009. "Pioneering Inventors or Thicket Builders: Which U.S. Firms Use Continuations in Patenting?" Management Science 55 (7): 1214-26.

-Heger, Diana, and Alexandra K. Zaby. 2013. "The Heterogeneous Costs of Disclosure and the Propensity to Patent." Oxford Economic Papers 65 (3): 630-52.

Helmers, Christian, and Luke McDonagh. 2012. "Patent Litigation in the UK." Law, Society and Economy Working Paper 12/2012.

Henkel, Joachim, and Stefanie Pangerl. 2008. "Defensive Publishing: An Empirical Study." http://papers. ssrn.com/sol3/papers.cfm?abstract_id=981444.

-Henry, Emeric, and Carlos J. Ponce. 2011. "Waiting to Imitate: On the Dynamic Pricing of Knowledge." Journal of Political Economy 119 (5): 959-81.

Henry, Emeric, and Francisco Ruiz-Aliseda. 2012. "Innovation Beyond Patents: Technological 
Complexity as a Protection against Imitation." Centre for Economic Policy Research Discussion Paper 8870 .

Holbrook, Timothy R. 2006. "Possession in Patent Law." SMU Law Review 59 (123): 28-30.

Horstmann, Ignatius, Glenn M. MacDonald, and Alan Slivinski. 1985. "Patents as Information Transfer Mechanisms: To Patent or (Maybe) Not to Patent." Journal of Political Economy 93 (5): 837-58.

Hounshell, David A. 1984. From the American System to Mass Production, 1800-1932: The Development of Manufacturing Technology in the United States. Baltimore: Johns Hopkins University Press.

Hsu, David H., and Rosemarie H. Ziedonis. 2008. "Patents as Quality Signals for Entrepreneurial Ventures." http://www.management.wharton.upenn.edu/ hsu/inc/doc/papers/david-hsu-signals.pdf.

-Hussinger, Katrin. 2006. "Is Silence Golden? Patents versus Secrecy at the Firm Level." Economics of Innovation and New Technology 15 (8): 735-52.

Hyytinen, Ari, and Mika Pajarinen. 2003. "External Finance, Firm Growth and the Benefits of Information Disclosure: Evidence from Finland." Research Institute of the Finnish Economy Discussion Paper 805.

Hyytinen, Ari, and Mika Pajarinen. 2005. "Financing of Technology-Intensive Small Businesses: Some Evidence on the Uniqueness of the ICT Sector." Information Economics and Policy 17 (1): 115-32.

Jensen, Paul H., and Elizabeth Webster. 2004. "Patterns of Trademarking Activity in Australia." Australian Journal of Intellectual Property 15 (2): 112-26.

-Jensen, Paul H., and Elizabeth Webster. 2009. "Knowledge Management: Does Capture Impede Creation?" Industrial and Corporate Change 18 (4): 701-27.

- Jovanovic, Boyan, and Glenn M. MacDonald. 1994. "The Life Cycle of a Competitive Industry." Journal of Political Economy 102 (2): 322-47.

Jung, Tachyun, and John P. Walsh. 2010. "What Drives Strategic Patenting? Evidence from the Georgia Tech Inventor Survey." Conference presentation to the AOM, Montreal and Korean Institute of Science and Technology.

Klepper, Steven. 1996. "Entry, Exit, Growth, and Innovation over the Product Life Cycle." American Economic Review 86 (3): 562-83.

Kultti, Klaus, Tuomas Takalo, and Juuso Toikka. 2006. "Simultaneous Model of Innovation, Secrecy, and Patent Policy." American Economic Review 96 (2): 82-86.

Kultti, Klaus, Tuomas Takalo, and Juuso Toikka. 2007. "Secrecy versus Patenting." RAND Journal of Economics 38 (1): 22-42.

Landes, William M., and Richard A. Posner. 2003. The Economic Structure of Intellectual Property Law. Cambridge, Mass. and London: Harvard University Press.

Lanjouw, Jean O., Ariel Pakes, and Jonathan Putnam. 1998. "How to Count Patents and Value Intellectual Property: The Uses of Patent Renewal and Application Data." Journal of Industrial Economics 46 (4):
405-32.

-Leiponen, Aija, and Justin Byma. 2009. "If You Cannot Block, You Better Run: Small Firms, Cooperative Innovation, and Appropriation Strategies." Research Policy 38 (9): 1478-88.

Lemley, Mark A. 2008. "Ignoring Patents." Michigan State Law Review 19: 19-34.

Lemley, Mark A. 2012. "The Myth of the Sole Inventor." Michigan Law Review 110 (5): 709-60.

Lemley, Mark A., and Carl Shapiro. 2005. "Probabilistic Patents." Journal of Economic Perspectives 19 (2): $75-98$.

Lerner, Josh. 2006. "Using Litigation to Understand Trade Secrets: A Preliminary Exploration.” http:// papers.ssrn.com/sol3/papers.cfm?abstract_id $=922520$.

Levin, Richard C., Alvin K. Klevorick, Richard R. Nelson, and Sidney G. Winter. 1987. "Appropriating the Returns from Industrial Research and Development." Brookings Papers on Economic Activity 3: 783-831.

Li, Xing, Megan MacGarvie, and Petra Moser. 2014. "Dead Poets' Property_Does Copyright Increase the Price of Content." http://papers.ssrn.com/sol3/ papers.cfm?abstract_id $=2170447$.

Lichtman, Douglas, Scott Baker, and Kate Kraus. 2000. "Strategic Disclosure in the Patent System." Vanderbilt Law Review 53: 2175-2217.

Llerena, Patrick, and Valentine Millot. 2013. "Are Trade Marks and Patents Complementary or Substitute Protections for Innovation." Bureau d'économie théorique et appliquée Document de Travail 2013-01.

Love, Brian J., and Christopher B. Seaman. 2012. "Best Mode Trade Secrets." Yale Journal of Law and Technology 15: 1-23.

-Mansfield, Edwin. 1986. "Patents and Innovation: An Empirical Study." Management Science 32 (2): 173-81.

- Mansfield, Edwin, Mark Schwartz, and Samuel Wagner. 1981. "Imitation Costs and Patents: An Empirical Study." Economic Journal 91 (364): 907-18.

Mazeh, Yoav, and Mark Rogers. 2006. "The Economic Significance and Extent of Copyright Cases: An Analysis of Large UK Firms." Intellectual Property Quarterly 4: 404-20.

Merges, Robert P. 2004. "A New Dynamism in the Public Domain." University of Chicago Law Review 71: 183-203.

Mosel, Malte. 2011. "Big Patents, Small Secrets: How Firms Protect Inventions When R\&D Outcome Is Heterogeneous." Bavarian Graduate Program in Economics Discussion Paper 105.

-Moser, Petra. 2005. "How Do Patent Laws Influence Innovation? Evidence from Nineteenth-Century World's Fairs." American Economic Review 95 (4): 1214-36.

-Moser, Petra. 2012. "Innovation without Patents: Evidence from World's Fairs." Journal of Law and Economics 55 (1): 43-74.

Moser, Petra. 2013. "Patents and Innovation: Evidence 
from Economic History." Journal of Economic Perspectives 27 (1): $23-44$.

Mowery, David C., Richard R. Nelson, Bhaven N. Sampat, and Arvids A. Ziedonis. 2004. Ivory Tower and Industrial Innovation: University-Industry Technology Transfer before and after the Bayh-Dole Act. Stanford: Stanford University Press.

Murmann, Johann Peter. 2003. Knowledge and Competitive Advantage: The Coevolution of Firms, Technology, and National Institutions. Cambridge and New York: Cambridge University Press.

Nagaoka, Sadao, and John P. Walsh. 2009. "Commercialization and Other Uses of Patents in Japan and the U.S.: Major Findings from the RIETI-Georgia Tech Inventor Survey." Research Institute of Economy, Trade and Industry Discussion Paper 09-E-011.

- Nuvolari, Alessandro. 2004. "Collective Invention during the British Industrial Revolution: The Case of the Cornish Pumping Engine." Cambridge Journal of Economics 28 (3): 347-63.

Olson, Mancur. 1971. The Logic of Collective Action: Public Goods and the Theory of Groups. Cambridge and London: Harvard University Press, 1965.

Ouellette, Lisa Larrimore. 2012. "Do Patents Disclose Useful Information?" Harvard Journal of Law and Technology 25 (2): 545-607.

Pajak, Serge. 2010. "Do Innovative Firms Rely on Big Secrets? An Analysis of IP Protection Strategies with the CIS 4 Survey." http://papers.ssrn.com/sol3/ Papers.cfm?abstract_id=1538980.

Pitkethly, Robert H. 2001. "Intellectual Property Strategy in Japanese and UK Companies: Patent Licensing Decisions and Learning Opportunities." Research Policy 30 (3): 425-42.

Png, I. P. L. 2011. "Law and Innovation: Evidence from the Uniform Trade Secrets Act." http:// www.fas.nus.edu.sg/ecs/events/seminar/seminarpapers/12Apr11.pdf.

Png, I. P. L., and Qiu-hong Wang. 2009. "Copyright Law and the Supply of Creative Work: Evidence from the Movies." http://www.comp.nus.edu.sg/ $\sim$ ipng/research/copyrt.pdf.

Ponce, Carlos J. 2007. "More Secrecy ... More Knowledge Disclosure? On Disclosure Outside of Patents." Universidad Carlos III de Madrid Departamento de Economia Working Paper 07-72.

-Ponce, Carlos J. 2011. "Knowledge Disclosure as Intellectual Property Rights Protection." Journal of Economic Behavior and Organization 80 (3): 418-34.

Rogers, Mark. 2007. "An Analysis of the Association between the Use of Intellectual Property By UK SMEs and Subsequent Performance." http://www. ipo.gov.uk/ipresearch-association-200710.pdf.

Rogers, Mark, and Christine Greenhalgh. 2006. "Use of Intellectual Property By the UK Financial Services Sector." In The Management of Intellectual Property, edited by Derek Bosworth and Elizabeth Webster, 200-220. Cheltenham and Northampton: Elgar.

-Romer, Paul M. 1990. "Endogenous Technological Change." Journal of Political Economy 98 (5 Part 2): S71-102.
-Salop, Steven C. 1979. "Monopolistic Competition with Outside Goods." Bell Journal of Economics 10 (1): 141-56.

- Samuelson, Pamela, and Suzanne Scotchmer. 2002. "The Law and Economics of Reverse Engineering." Yale Law Journal 111 (7): 1575-1663.

Scherer, Frederic M. 1998. "The Size Distribution of Profits from Innovation." Annales d'Economie et de Statistique 49-50: 495-516.

Schmookler, Jacob. 1966. Invention and Economic Growth. Cambridge and London: Harvard University Press.

- Schneider, Cédric. 2008. "Fences and Competition in Patent Races." International Journal of Industrial Organization 26 (6): 1348-64.

- Scotchmer, Suzanne, and Jerry Green. 1990. "Novelty and Disclosure in Patent Law." RAND Journal of Economics 21 (1): 131-46.

Seethamraju, Chandrakanth. 2003. "The Value Relevance of Trademarks." In Intangible Assets: Values, Measures, and Risks, edited by John R. M. Hand and Baruch Lev, 228-47. Oxford and New York: Oxford University Press.

Sichelman, Ted, and Stuart J. H. Graham. 2010. "Patenting By Entrepreneurs: An Empirical Study." Michigan Telecommunications and Technology Law Review 17 (1): 111-80.

U.S. National Science Foundation. 2012. "Business Use of Intellectual Property Protection Documented in NSF Survey." National Science Foundation InfoBrief 12-307.

-von Graevenitz, Georg, Stefan Wagner, and Dietmar Harhoff. 2011. "How to Measure Patent ThicketsA Novel Approach.” Economics Letters 111 (1): 6-9.

-Waldfogel, Joel. 2012. "Copyright Protection, Technological Change, and the Quality of New Products: Evidence from Recorded Music since Napster." Journal of Law and Economics 55 (4): 715-40.

Walsh, John P., and Sadao Nagaoka. 2009. "How 'Open' Is Innovation in the U.S. and Japan?: Evidence from the RIETI-Georgia Tech Inventor Survey." Research Institute of Economy, Trade and Industry Discussion Paper 09-E-022.

Wright, Brian D. 1983. "The Economics of Invention Incentives: Patents, Prizes, and Research Contracts." American Economic Review 73 (4): 691-707.

Younge, Kenneth A., and Matt Marx. 2012. "The Market Value of Knowledge Protection: Evidence from a Natural Experiment." http://funginstitute. berkeley.edu/sites/default/files/Younge\%20Marx\%20 2012\%20-\%20Working\%20Paper\%20-\%20The\%20 Market\%20Value\%20of\%20Knowledge\%20Protection\%20Jan\%2010\%202012.pdf.

Zaby, Alexandra K. 2010. "Losing the Lead: The Patenting Decision in the Light of the Disclosure Requirement." Economics of Innovation and New Technology 19 (2): 147-64.

Zhao, Minyuan. 2006. "Conducting R\&D in Countries with Weak Intellectual Property Rights Protection." Management Science 52 (8): 1185-99. 